\title{
nombalina
}

(8)

\section{Investigação das bases biológicas da cognição na esquizofrenia com Imagiologia} Genética

\author{
Autor(es): $\quad$ Prata, Diana P. \\ Publicado por: Imprensa da Universidade de Coimbra \\ URL \\ persistente: URI:http://hdl.handle.net/10316.2/35961 \\ DOI: $\quad$ DOI:http://dx.doi.org/10.14195/978-989-26-0852-5_8 \\ Accessed : $\quad$ 26-Apr-2023 16:03:39
}

A navegação consulta e descarregamento dos títulos inseridos nas Bibliotecas Digitais UC Digitalis, UC Pombalina e UC Impactum, pressupõem a aceitação plena e sem reservas dos Termos e Condições de Uso destas Bibliotecas Digitais, disponíveis em https://digitalis.uc.pt/pt-pt/termos.

Conforme exposto nos referidos Termos e Condições de Uso, o descarregamento de títulos de acesso restrito requer uma licença válida de autorização devendo o utilizador aceder ao(s) documento(s) a partir de um endereço de IP da instituição detentora da supramencionada licença.

Ao utilizador é apenas permitido o descarregamento para uso pessoal, pelo que o emprego do(s) título(s) descarregado(s) para outro fim, designadamente comercial, carece de autorização do respetivo autor ou editor da obra.

Na medida em que todas as obras da UC Digitalis se encontram protegidas pelo Código do Direito de Autor e Direitos Conexos e demais legislação aplicável, toda a cópia, parcial ou total, deste documento, nos casos em que é legalmente admitida, deverá conter ou fazer-se acompanhar por este aviso.

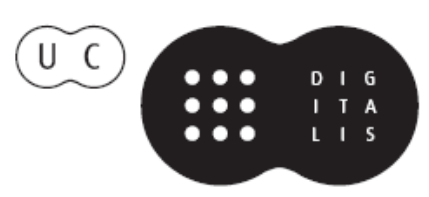





\section{NVESTIGAÇÃO DAS BASES BIOLÓGICAS DA COGNIÇÃO NA ESQUIZOFRENIA COM IMAGIOLOGIA GENÉTICA}

\section{Imagiologia genética}

A imagiologia genética é uma área de investigação recente que usa a genética quantitativa para medir a hereditariedade de um endofenótipo (ou fenótipo intermédio) imagiológico e a genética molecular para identificar os exatos variantes genéticos a ele associados. O endofenótipo imagiológico pode ser funcional (uma resposta fisiológica do cérebro durante o processamento de informação) ou estrutural (volume cerebral regional ou total, integridade da matéria branca, etc.). Em termos da estrutura cerebral, estudos de imagiologia genética quantitativa já mostraram que a espessura da matéria cinzenta cortical é tanto maior quanto maior o grau de afinidade genética entre indivíduos (Thompson et al., 2001). A hereditariedade da redução do volume da matéria cinzenta cortical e do hipocampo, que está presente na esquizofrenia, também já foi calculada e é considerável (Goldman et al., 2008). (Estudos de hereditariedade no âmbito da imagiologia funcional serão mencionados mais adiante).

Dando seguimento a essas descobertas, a imagiologia genética molecular tem contribuído para a caracterização do impacto de variações genéticas previamente associadas à esquizofrenia na função e na estru-

1 (PhD), Bióloga investigadora no Departamento de Estudos sobre Psicoses do Instituto de Psiquiatria de Londres, parte do King'sCollege of London da Universidade de Londres, Reino Unido. E-mail: diana.prata@kcl.ac.uk 
tura do cérebro. Ou seja, uma vez identificada uma variação genética que influencia a susceptibilidade para a esquizofrenia, e idealmente com conhecido impacto funcional (a nível molecular/celular), torna-se interessante testar a sua associação aos dados imagiológicos (Hariri \& Weinberger, 2003b) (Figura 1). Ao utilizar endofenótipos da esquizofrenia, a imagiologia genética tem vantagens sobre estudos (epidemiológicos) de associação genética: permite um foco mais preciso nos processos metabólicos que estão alterados na esquizofrenia e por isso, permite a construção de hipóteses mais específicas. A assunção é a de que polimorfismos genéticos que estão subtilmente relacionados com fenótipos psiquiátricos complexos (ex., a esquizofrenia), ou outros endofenótipos comportamentais (ex., défice cognitivo, apatia, etc.), podem estar mais fortemente relacionados com (i.e. deverão ter maior penetrância em) aspectos da função e estrutura do cérebro. Esta premissa acrescida ao facto de que a imagiologia providencia, para cada sujeito, uma enorme quantidade de dados potencialmente caracterizadores do impacto de variações genéticas no cérebro, pode traduzir-se num acréscimo considerável de poder estatístico. Isto é especialmente relevante dado que a vasta maioria das variações genéticas em causa demonstram um efeito de muito pequena magnitude (rácio de probabilidade $<1.5$ ) em termos da sua associação direta (epidemiológica) com a esquizofrenia. Em comparação com um determinado endofenótipo comportamental, o endofenótipo imagiológico desse mesmo comportamento - realizado dentro de scanner de ressonância magnética funcional ('functional magnetic resonance imaging' - FMRI) ou de tomografia por emissão de positrões ('positron emission tomographi', PET) - tem a vantagem de medir a sua natureza neurofisiológica. Daí advém maior sensibilidade estatística, maior objectividade na medição e a possibilidade de detectar estratégias neuronais diferentes em diferentes indivíduos mas que levam ao mesmo desempenho/comportamento (Hariri et al., 2003b).

$\mathrm{Na}$ última década, vários estudos de imagiologia genética molecular reportaram associações entre polimorfismos específicos (a maioria, funcionais, i.e. que induzem mudanças a nível metabólico) e padrões de ativação cerebral. Estes demonstraram que a neuroimagiologia funcional 


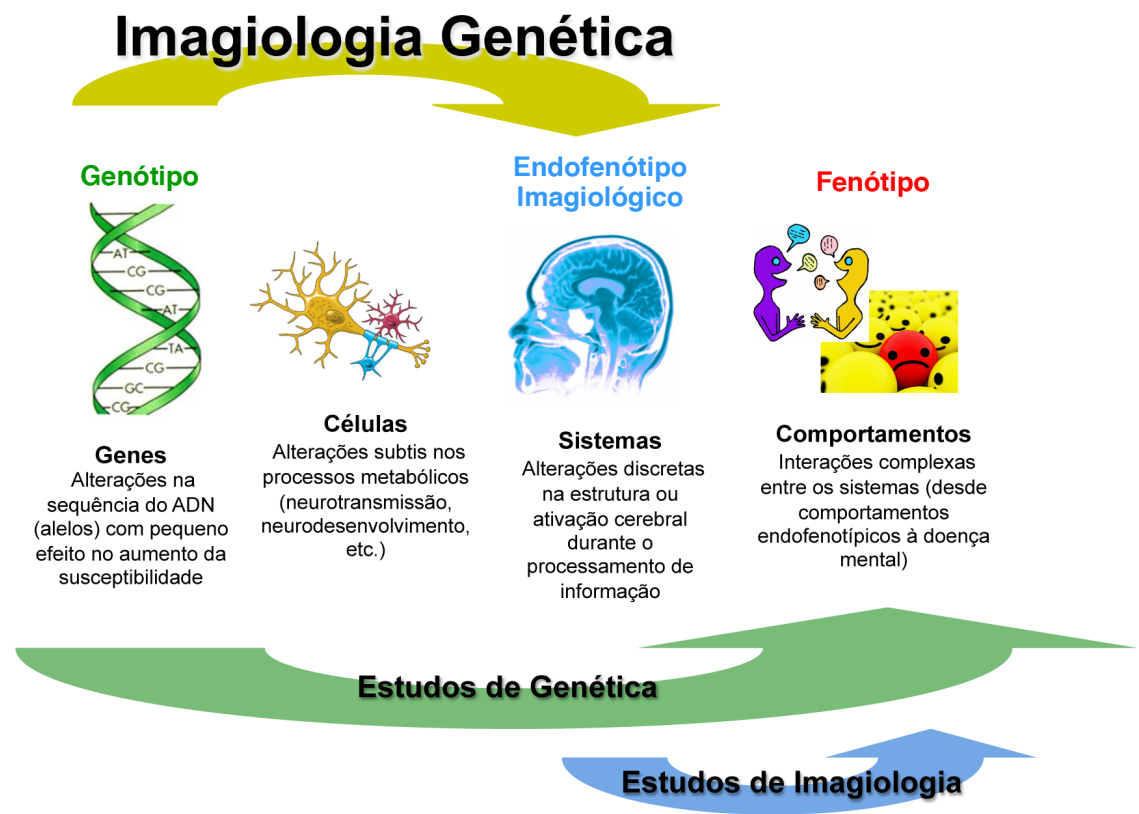

Figura 1. Racional da imagiologia genética. Estabelecidas já associações entre genes e comportamentos bem como entre aspectos estruturais e funcionais do cérebro e comportamentos, a imagiologia genética veio estudar o impacto de variações genéticas na estrutura e função do cérebro. Dado que o impacto dos genes no comportamento tem forçosamente que passar pelo cérebro, é plausível que tal estratégia possibilite uma melhor caraterização da etiologia genética do comportamento (e das doenças mentais).

consegue de facto distinguir entre indivíduos de baixo e de alto risco genético para um determinado endofenótipo ou fenótipo mesmo sendo assintomáticos a nível comportamental (Small, 2006; Whalley et al., 2006). O uso pioneiro desta abordagem foi por Bookheimer et al. (Bookheimer et al., 2000), em que 30 indivíduos neurologicamente saudáveis foram submetidos a uma tarefa de memória declarativa enquanto eram scaneados com fMRI. Os 16 sujeitos que tinham pelo menos uma cópia do alelo e4 da apolipoproteína, um alelo fortemente associado à doença de Alzheimer, mostraram uma ativação significativamente maior em regiões tipicamente afectadas pela doença do que os indivíduos com duas cópias do alelo protetor (e3). Desde então, tem-se vindo a acumular evidência 
de que marcadores da função do cérebro podem ser mais sensíveis a variações subtis em genes envolvidos na neurotransmissão (Smolka et al., 2005; Hariri, Mattay, Tessitore, Fera \& Weinberger, 2003; Mattay et al., 2003; Pezawas et al., 2005; Egan et al., 2001b) ou neurodesenvolvimento (McKiernan, D’Angelo, Kaufman, \& Binder, 2006; Hariri et al., 2003a) do que marcadores comportamentais (Tabela 1).

Tabela 1. Lista selecionada de associações positivas originais em estudos de neuroimagiologia genética funcional até final de 2009.

\begin{tabular}{|c|c|c|c|}
\hline \multicolumn{4}{|c|}{ ESTUDOS DE NEURO-IMAGIOLOGIA GENÉTICA MOLECULAR } \\
\hline Autores & Marcador Genético & Região Cerebral & Tarefa \\
\hline $\begin{array}{l}\text { (Bookheimer } \\
\text { et al., 2000) }\end{array}$ & APOE $\varepsilon 3 / 4$ & $\begin{array}{l}\text { Hipocampo, córtex } \\
\text { pré-frontal e parietal }\end{array}$ & Memória \\
\hline $\begin{array}{l}\text { (Egan et al., } \\
2001 b)\end{array}$ & COMT Val158Met & Córtex pré-frontal & $\begin{array}{c}\text { Memória de trabalho } \\
\text { ('N-back') }\end{array}$ \\
\hline $\begin{array}{l}\text { (Hariri et al., } \\
\text { 2002) }\end{array}$ & 5HHTPR InDel & Amígdala & $\begin{array}{c}\text { Reconhecimento facial } \\
\text { de emoções }\end{array}$ \\
\hline $\begin{array}{l}\text { (Hariri et al., } \\
\text { 2003a) }\end{array}$ & BDNF Val66Met & Hipocampo & Memória episódica \\
\hline $\begin{array}{l}\text { (Mattay et al., } \\
\text { 2003) }\end{array}$ & $\begin{array}{c}\text { COMT Val158Met x } \\
\text { Anfetamina }\end{array}$ & Córtex pré-frontal & $\begin{array}{c}\text { Memória de trabalho } \\
\text { ('N-back') }\end{array}$ \\
\hline $\begin{array}{c}\text { (Pezawas et al., } \\
\text { 2005) }\end{array}$ & 5-HTTLPR Indel & $\begin{array}{c}\text { Conectividade } \\
\text { funcional amígdala- } \\
\text { cingulado }\end{array}$ & $\begin{array}{c}\text { Reconhecimento facial } \\
\text { de emoções }\end{array}$ \\
\hline $\begin{array}{c}\text { (Smolka et al. } \\
\text { 2005) }\end{array}$ & COMT Val158Met & $\begin{array}{l}\text { Amígdala,córtex } \\
\text { pré-frontal }\end{array}$ & $\begin{array}{c}\text { Resposta afectiva a } \\
\text { estímulos visuais }\end{array}$ \\
\hline $\begin{array}{l}\text { (Callicott } \text { et al., } \\
\text { 2005) }\end{array}$ & DISC1 Ser704Cys & Hipocampo & $\begin{array}{c}\text { Memória de trabalho } \\
\text { ('N-back') }\end{array}$ \\
\hline $\begin{array}{c}\text { (Bertolino et al. } \\
\text { 2006a) }\end{array}$ & $\begin{array}{l}\text { COMT Val158Met x } \\
\text { DAT 10' UTR VNTR }\end{array}$ & $\begin{array}{l}\text { Córtex pré-frontal, } \\
\text { cingulado anterior }\end{array}$ & $\begin{array}{l}\text { Memória de trabalho } \\
\text { ('N-back') e episódica }\end{array}$ \\
\hline $\begin{array}{c}\text { (Meyer- } \\
\text { Lindenberg } \\
\text { et al., 2006) }\end{array}$ & COMT (haplótipos) & Córtex pré-frontal & $\begin{array}{c}\text { Memória de trabalho } \\
\text { ('N-back') }\end{array}$ \\
\hline $\begin{array}{c}\text { (Heinz et al., } \\
\text { 2005) }\end{array}$ & 5-HTTLPR Indel & $\begin{array}{c}\text { Conectividade } \\
\text { funcional amígdala- } \\
\text { Córtexpré-frontal }\end{array}$ & $\begin{array}{c}\text { Resposta afectiva a } \\
\text { estímulos visuais }\end{array}$ \\
\hline
\end{tabular}




\begin{tabular}{|c|c|c|c|}
\hline \multicolumn{4}{|c|}{ ESTUDOS DE NEURO-IMAGIOLOGIA GENÉTICA MOLECULAR } \\
\hline Autores & Marcador Genético & Região Cerebral & Tarefa \\
\hline $\begin{array}{l}\text { (Prata et al. } \\
\text { 2008) }\end{array}$ & DISC1 Ser704Cys & Córtex pré-frontal & Fluência verbal \\
\hline $\begin{array}{l}\text { (Hall et al., } \\
\text { 2006) }\end{array}$ & NRG1 rs6994992 & Córtex pré-frontal & Finalização de frases \\
\hline $\begin{array}{c}\text { (Kempf et al., } \\
\text { 2008) }\end{array}$ & PRODH (haplótipos) & $\begin{array}{c}\text { Conectividade } \\
\text { funcional estriado- } \\
\text { córtex }\end{array}$ & $\begin{array}{c}\text { Memória de trabalho } \\
\text { ('N-back') }\end{array}$ \\
\hline $\begin{array}{c}\text { (Buckholtz et } \\
\text { al., 2007) }\end{array}$ & $\begin{array}{l}\text { COMT Val158Met x } \\
\text { RGS4 rs951436 }\end{array}$ & Córtex pré-frontal & $\begin{array}{c}\text { Memória de trabalho } \\
\text { ('N-back') }\end{array}$ \\
\hline $\begin{array}{c}\text { (Yacubian et al., } \\
\text { 2007) }\end{array}$ & $\begin{array}{l}\text { COMT Val158Met x } \\
\text { DAT 10' UTR VNTR }\end{array}$ & Estriado ventral & Adivinha-recompensa \\
\hline $\begin{array}{c}\text { (Buckholtz et } \\
\text { al., 2008) }\end{array}$ & MAOA 30-bp VNTR & $\begin{array}{l}\text { Conectividade } \\
\text { funcional amígdala- } \\
\text { córtex pré-frontal }\end{array}$ & $\begin{array}{l}\text { Evitação de danos, } \\
\text { Recompensa }\end{array}$ \\
\hline $\begin{array}{c}\text { (Prata et al. } \\
\text { 2009b) }\end{array}$ & DAT 10' UTR VNTR & $\begin{array}{c}\text { Córtex pré-frontal e } \\
\text { estriado }\end{array}$ & Fluência verbal \\
\hline $\begin{array}{c}\text { (Prata et al. } \\
\text { 2009c) }\end{array}$ & COMT Val158Met & Córtex peri-Silviano & Fluência verbal \\
\hline $\begin{array}{c}\text { (Prata et al., } \\
\text { 2009a) }\end{array}$ & $\begin{array}{l}\text { COMT Val158Met } \mathrm{x} \\
\text { DAT 10' UTR VNTR }\end{array}$ & Córtex supramarginal & Fluência verbal \\
\hline
\end{tabular}

\subsection{Fluência verbal}

A fluência verbal é uma tarefa que mede a capacidade de reproduzir palavras após sugestão da primeira letra. Ruff et al., (1986) relacionam a fluência verbal com a memória de curto-prazo, a atenção verbal, a memória semântica e processos executivos como a iniciação e a reprodução estratégica. A tarefa de fluência verbal tem sido extensivamente usada em estudos neuropsicológicos da esquizofrenia em que os doentes tipicamente produzem menos palavras que indivíduos saudáveis (Bokat \& Goldberg, 2003; Henry \& Crawford, 2005). A fluência verbal parece estar fortemente correlacionada com os sintomas negativos da esquizofrenia (Howanitz, Cicalese \& Harvey, 2000) e melhorar depois de tratamento 
com antipsicóticos atípicos como a clozapina (Meltzer \& McGurk, 1999). Parentes não afectados de doentes com esquizofrenia desempenham a tarefa a um nível intermédio entre doentes e indivíduos controlo (sem parentes doentes), o que sugere, embora não demonstre, hereditariedade deste potencial endofenótipo (Chen, Yu, Chen, Mak \& Lieh, 2000; Sitskoorn, Aleman, Ebisch, Appels \& Kahn, 2004; Aukes et al., 2008). Outro traço relacionado com a fluência verbal, a memória verbal, também já demonstrou risco familiar (Sponheim, Steele \& McGuire, 2004; Egan et al., 2001a; Faraone et al., 2000; Toomey et al., 1998; Kremen et al., 1994; Goldberg et al., 1990). Défices na aprendizagem verbal e memória até já foram mapeados à região cromossómica 4q21 (Paunio et al., 2004).

Vários métodos têm sido usados para medir a atividade cerebral (Papanicolaou, 1998), e.g., magnetoencefalografia (MEG), electroencefalografia (EEG), tomografia por emissão de fotão único ('single photon emission computed tomography', SPECT), PET ou fMRI. A PET usa compostos agonistas rádio-marcados ('radio-labeled') para localizar regiões onde há ocupação de receptores, ao longo do tempo. A ressonância magnética (fMRI) usa, mais frequentemente, um sinal dependente do nível de oxigénio do sangue ('bloodoxygenlevel-dependent', BOLD). Isto permite avaliar os processos cognitivos através do mapeamento da ativação da rede inteira de áreas cerebrais requisitados por uma tarefa ou estímulo, numa sequência temporal de imagens. Em indivíduos saudáveis, os primeiros estudos PET para a fluência verbal reportaram que a ativação do córtex pré-frontal dorso-lateral esquerdo (maior durante a geração de palavras) estava negativamente correlacionada com a ativação do giro temporal superior bilateral (maior durante a repetição de palavras, i.e. a tarefa controle) (Spence et al., 2000). A fMRI também tem reportado ativação mais frequentemente no córtex frontal inferior e médio esquerdo e também no córtex cingulado, insular, pré-central, temporal superior e parietal (Fu et al., 2002). A ativação nos córtices pré-frontais é mais proeminente no hemisfério esquerdo (Fu et al., 2002). Tal é consistente com o giro frontal inferior esquerdo incluir a clássica área de Broca e, em conjunto com a ínsula, está envolvido na compreensão e produção da linguagem como tem sido demostrado por estudos neurofisiológicos 
(em lesões) bem como imagiológicos (Costafreda et al., 2006; Fiez \& Petersen, 1998; Damasio \& Damasio, 1992). Áreas homólogas a estas no hemisfério direito também estão frequentemente ativas durante tarefas de linguagem (Gernsbacher \& Kaschak, 2003; Damasio et al., 1992) embora o seu papel durante a produção de palavras seja mais disputado (Price \& Crinion, 2005).

A fluência verbal, com a memória de trabalho, é a tarefa cognitiva mais usada em imagiologia funcional para a investigação da esquizofrenia. Alguns estudos de PET sugerem uma disconectividade fronto-temporal cortical durante a fluência verbal nos doentes, i.e. uma conectividade anormal (por ser positiva) entre o córtex pré-frontal e o temporal esquerdos, causada por uma falha em desativar o giro superior temporal esquerdo ou ambos (Friston \& Frith, 1995), embora existam estudos que não encontraram diferenças (Spence et al., 2000). Esta lateralização reduzida na esquizofrenia também já foi observada com fMRI (Weiss et al., 2004; Sommer, Ramsey \& Kahn, 2001). Tal não parece incluir uma ativação reduzida do córtex frontal esquerdo per se (Sommer et al., 2001), embora certos estudos tenham reportado um decréscimo na ativação do cingulado anterior e córtices frontais médios e inferiores (Fu et al., 2005). Este último tipo de resultado, no entanto, não foi controlado para os diferentes níveis de desempenho conseguidos entre os indivíduos (i.e. palavras corretas versus incorretas) e por isso, pode dever-se em parte a uma falta de atenção/concentração ou comprometimento na tarefa, ambas frequentes na esquizofrenia.

Estudos de fMRI parecem indicar que tanto os gémeos não psicóticos de doentes com esquizofrenia como os sujeitos apresentando um estado mental de alto risco para a psicose (i.e. pródromo) mostram alterações na ativação cortical durante a fluência verbal que são qualitativamente semelhantes às encontradas na esquizofrenia (MacDonald, III; Broome et al., 2008; Becker \& Carter, 2006; Whyte et al., 2006; Sommer, Ramsey, Mandl, van Oel \& Kahn, 2004; Sommer et al., 2004; Picchioni et al., 2001; Picchioni et al., 2001). Isto sugere, embora não demonstre, hereditariedade e um status de independência da ocorrência ('state-independence') da esquizofrenia para este traço cognitivo. O mesmo foi reportado para 
uma tarefa relacionada, a memoria declarativa verbal (Whyte et al., 2006), e com a memória de trabalho (Karlsgodt et al., 2007; Callicott et al., 2003), em que os doentes com esquizofrenia e os seus irmãos saudáveis requereram maior ativação no córtex pré-frontal dorso-lateral para atingir o mesmo nível de desempenho que os sujeitos controlo (saudáveis e sem risco familiar para a doença). De facto, híper-ativação (supostamente ineficiente) durante a memória de trabalho já demonstrou ter uma hereditariedade alta (de $80 \%$ nas zonas do cérebro relacionadas com a linguagem) (Koten, Jr. et al., 2009). Em suporte destes resultados, a densidade de matéria cinzenta nas áreas frontocorticais relacionadas com a linguagem em ambos os hemisférios mostrou também ser influenciada por factores genéticos (Glahn, Bearden, Niendam \& Escamilla, 2004). No geral, estas descobertas são consistentes com a hipótese de o padrão de ativação anómalo recrutado durante a fluência verbal em doentes esquizofrénicos ser um marcador endofenotípico do risco para a doença, ou, pelo menos um fenótipo intermédio (i.e. dado que não há ainda evidência da observação de todos os critérios necessários).

Seguem-se exemplos de estudos de imagiologia genética em que se procurou saber se polimorfismos genéticos previamente associados à esquizofrenia eliciariam diferenças no padrão de ativação cerebral durante a fluência verbal mesmo em indivíduos saudáveis e se essas diferenças seriam distintas em doentes com esquizofrenia. Os sujeitos destes estudos desempenharam oralmente a tarefa de fluência verbal em duas versões (ou sub-tarefas): uma fácil e uma difícil. Nestas versões, ambas correspondendo à condição de interesse, i.e. a geração de palavras, foi requerido aos sujeitos que articulassem dentro de 4 segundos depois da apresentação de cada letra uma palavra que começasse com a respectiva letra. Em cada região do cérebro, à ativação cerebral durante esta tarefa foi subtraída a ativação requisitada pela tarefa-controle, i.e. a repetição de palavras, em que foi pedido aos sujeitos que lessem uma vez, também em voz-alta, a palavra 'REST' (para mais detalhes sobre o design da tarefa, ver Figura 2). Testes em que os sujeitos não geraram qualquer resposta ou geraram uma resposta incorreta, ex., nomes próprios, palavras repetidas, derivadas ou variações gramaticais de palavras prévias foram 
modelados separadamente na análise estatística. Tal foi feito de modo excluir da análise diferenças na ativação cerebral que se possam dever a diferenças no desempenho; entre outras razões, porque a variabilidade no desempenho pode advir de factores sem interesse para este estudo (ou factores de confusão, na gíria estatística) tais como a falta de atenção ou de participação na tarefa.

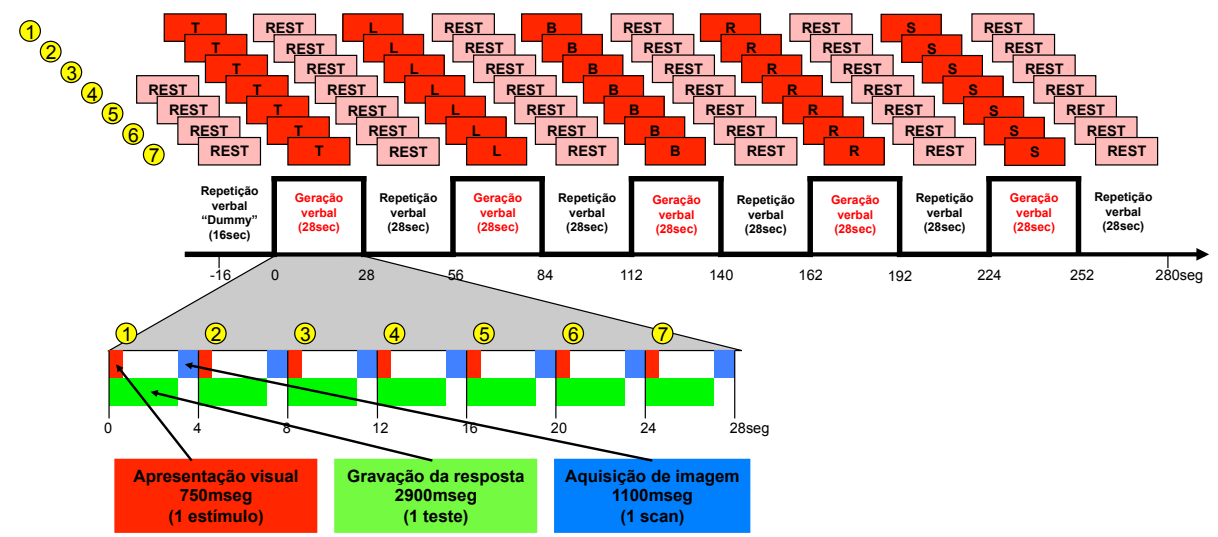

Figura 2. Representação esquemática do design em bloco usado em cada versão (difícil ou fácil) da tarefa de fluência verbal, com um zoom in no $1 .^{\circ}$ bloco de letras. Na versão fácil, foi apresentado visualmente aos sujeitos um de dois conjuntos de letras: 'T, L, B, R, S' ou 'T, C, B, P, S'; e na versão difícil: 'O, A, N, E, G' ou 'I, F, N, E, G'. A mesma letra (ou a palavra 'REST' no caso da tarefa-controlo), foi sequencialmente repetida 7 vezes (i.e. testes). Uma sequência total (fácil ou difícil) consistiu em 70 testes (35 de geração de palavras +35 de repetição de palavras) que correspondeu a 70 scans. Como cada teste demorava 4 segundos, cada sequência durou 280 segundos. Os primeiros scans adquiridos (chamados 'dummy-scans' e correspondentes a 4 testes da tarefa-controle durante os primeiros 16 segundos da sequência) foram removidos antes do pré-processamento das imagens, pois o seu propósito é apenas o de estabelecer condições estáveis (ex., temperatura) no scanner.

A fMRI distingue regiões com base em diferenças no nível de oxigenação do sangue ('blood oxygenation level dependent, BOLD'). Quando os neurónios disparam precisam de energia rapidamente. Num processo chamado resposta hemodinâmica, glucose e oxigénio (transportado pela hemoglobina) passam do sangue para os neurónios ativos a uma taxa 
maior do que para os neurónios inativos. A profusão de oxigénio (causada pela vasodilatação e o fluxo sanguíneo acrescido) está associada a um acréscimo de atividade neuronal e ultrapassa ligeiramente a quantidade requerida (i.e. a oxi-hemoglobina providenciada é maior que a oxi-hemoglobina usada (provavelmente de modo a haver um gradiente de pressão do sangue para o neurónio). É a descida consequente dos níveis locais de deoxi-hemoglobina que é medida (aliás, mais especificamente, é a resposta desta molécula paramagnética à presença de um campo magnético que é medida) (Papanicolaou, 1998). Os estudos apresentados de seguida mediram o contraste BOLD num scâner de 1.5 Tesla no Maudsley Hospital, London, U.K. O pré-processamento e análise estatística foram executados com o software SPM5 (Friston, 2003) (http//www.fil.ion.ucl.ac.uk/spm), seguindo o modelo linear geral ('general linear model', GLM). Uma análise de variância (ANOVA) (Penny, Holmes \& Friston, 2003) com grupo diagnóstico (indivíduos saudáveis versus doentes com esquizofrenia) e genótipo como factores independentes permitiu determinar o efeito principal do diagnóstico, o efeito principal do genótipo e a sua interação (diagnóstico x genótipo) na ativação regional durante a geração de palavras (subtraída pela activação durante a repetição de palavras). A significância estatística foi calculada com valor-p (i.e. a probabilidade de obter um resultado pelo menos tão extremo como o observado, sendo a hipótese nula verdadeira). A hipótese nula foi rejeitada - i.e. o resultado considerado estatisticamente significativo - quando $\mathrm{p}<0.05$ após correção para testes múltiplos do tipo FDR (false discovery rate) ou FWE (family-wise error) (ao nível do voxel). Quando não corrigido, o resultado foi denominado como 'tendência' se observasse um p<0.001 (sem correção). Para confirmar que o quociente de inteligência, os anos de educação, o sexo, a etnia, a idade ou o tipo e dose de medicação não influenciaram os resultados, foi sistematicamente realizada uma análise extra usando as variáveis demográficas que não se encontravam equilibradas entre os grupos genotípicos ou os diagnósticos, bem como as respeitantes à medicação, como co-variáveis sem interesse (e consequentemente, a sua influência na ativação foi estatisticamente removida). 


\subsubsection{Efeito da COMT - Incluído em Prata D. P. et al. Opposite effects of catechol-O-methyltransferase Val158Met on cortical function in healthy subjects and patients with schizophrenia. Biological Psychiatry, 2009 Mar 15;65 (6): 473-80 (Prata et al., 2009c)}

Acatecol-O-metiltransferase(COMT) é uma enzima que catalisa a O-metilação da dopamina inter-sináptica no cérebro (Tunbridge, Harrison \& Weinberger, 2006). Manifesta-se maioritariamente ligada à membrana ('Membrane-bound', MB-COMT) em neurónios pós-sinápticos (Tunbridge et al., 2006) no cérebro inteiro mas em níveis mais elevados nos córtices frontal e temporal do que nas zonas subcorticais (Tunbridge et al., 2006). A dopamina é também removida do espaço sináptico pelo transportador da dopamina (DAT) presente nos neurónios pré-sinápticos, mas sendo este transportador mais abundante nas áreas subcorticais do que nas corticais, a COMT tem uma influência relativamente maior nestas últimas (Tunbridge et al., 2006). A atividade enzimática da COMT é alterada pela substituição dum nucleótido contendo uma guanina (G) por outro contendo uma adenina (A) na sequência de ADN (ácido desoxirribonucleico) do gene que a codifica. Esta variação nucleotídica ('single nucleotide polymorphism', SNP) é designada por Val158Met, e catalogada como rs4680, dado que se traduz na substituição do aminoácido valina pelo aminoácido metioninana enzima (na posição correspondente ao codão 158 do RNA mensageiro). Este polimorfismo causa um decréscimo de 3 a 4 vezes na termo-estabilidade molecular da enzima. Os alelos são codominantes dado que o genótipo heterozigótico (Val158/Met158) apresenta um nível intermédio de integridade enzimática (que se traduz em concentração enzimática) tanto em enzimas sintetizadas in vitro como extraídas postmortem do córtex pré-frontal (Chen et al., 2004).

Na população saudável, o polimorfismo Val158Met está associado a diferenças estatisticamente significativas no desempenho de tarefas cognitivas (Diamond, Briand, Fossella \& Gehlbach, 2004; Goldberg et al., 2003; Malhotra et al., 2002; Egan et al., 2001b) e na ativação cortical durante a execução dessas tarefas, pelo menos no caso da memória de trabalho (Bertolino et al., 2006c; Bertolino et al., 2006b; Winterer et 
al., 2006; Blasi et al., 2005; Bertolino et al., 2004; Egan et al., 2001b). Pensa-se que isso reflete o impacto que o polimorfismo tem na atividade enzimática pois esta, ao afectar os níveis de dopamina sináptica disponível, deve influenciar a eficiência dessa região cortical (Tunbridge et al., 2006; Abi-Dargham \& Moore, 2003). O efeito da variação Val158Met na ativação pode também depender do nível local de atividade dopaminérgica aferente. Por exemplo, tal efeito é alterado depois da administração experimental de anfetamina, a qual aumenta a libertação sináptica da dopamina (Meyer-Lindenberg \& Weinberger, 2006; Mattay et al., 2003).

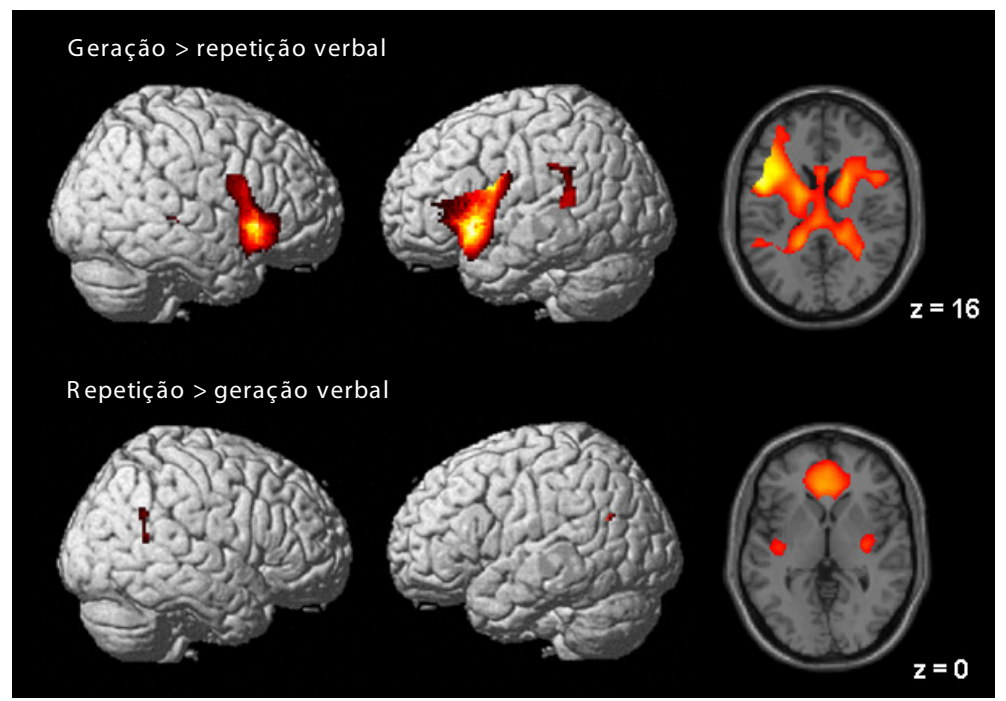

Figura 3. Ativação comum a doentes com esquizofrenia e indivíduos saudáveis no desempenho da tarefa de fluência verbal (significância estatística após correção para teste múltiplos FDR e FWE no cérebro inteiro p<0.05).

A esquizofrenia está associada a alterações no input dopaminérgico para o córtex cerebral (Akil et al., 2003; Abi-Dargham et al., 2002) e para o estriado (Meyer-Lindenberg et al., 2002; Bertolino et al., 2000; Grace, 2000). Dado que COMTVal158Met modula a ativação cortical durante tarefas cognitivas (nomeadamente a memória de trabalho) (Bertolino et al., 2006c; Bertolino et al., 2006b; Winterer et al., 2006; Blasi et al., 2005; 
Bertolino et al., 2004; Egan et al., 2001b), nós testámos a hipótese de que o polimorfismo também influenciaria significativamente a ativação cortical durante uma tarefa de fluência verbal (descrita em 1.1), usando fMRI. Também investigámos se tal seria significativamente diferente entre doentes com esquizofrenia e indivíduos saudáveis, refletindo possivelmente a perturbação na função dopaminérgica central associada à doença. Em comum, todos os sujeitos mostraram uma ativação bilateral nos córtices frontal inferior, insular e cingulado, no núcleo caudato e tálamo, bem como uma ativação à esquerda nos córtices frontal médio, temporal superior e parietal inferior e desativação no precúneo e no giro cingulado anterior rostral (Figura 3).

Os doentes mostraram maior ativação no opérculo frontal, na ínsula anterior e no giro frontal inferior esquerdos do que indivíduos saudáveis (Figura 4). Estas são áreas cuja ativação é fundamental na produção de linguagem e correspondem à área de Broca. Maior ativação pré-frontal em doentes do que em indivíduos saudáveis já havia sido reportada em estudos de memória de trabalho corrigidos para as diferenças no desempenho (Bertolino et al., 2006b; Perlstein, Carter, Noll \& Cohen, 2001; Manoach et al., 2000; Callicott et al., 2000), e interpretada como um reflexo de uma maior ineficiência pré-frontal proveniente da reduzida atividade dopaminérgica aferente que se pensa existir na esquizofrenia (Perlstein et al., 2001). Como já foi mencionado, a observação oposta ou inconclusiva de outros estudos de fluência verbal deve-se provavelmente a um controlo insuficiente das diferenças no desempenho da tarefa, senão a um fraco poder estatístico (Fu et al., 2005). Sendo que o nosso estudo teve a amostra maior até à data de publicação e restringiu a análise às imagens correspondentes apenas a respostas corretas, não sofre essas limitações.

A híper-ativação do córtex pré-frontal esquerdo relativamente à ativação temporal durante a fluência verbal foi um dos resultados originais que levou à já mencionada hipótese da disconectividade da esquizofrenia (Friston et al., 1995). Neste contexto, um aumento da ativação frontal pode ser vista, heuristicamente, como uma tentativa compensatória pelas regiões frontais para superar uma anómala ou reduzida capacidade de 
influência sobre outras regiões. Esta reduzida influência pode estar relacionada com a anómala função dopaminérgica central na esquizofrenia. (Fletcher, Frith, Grasby, Friston \& Dolan, 1996).
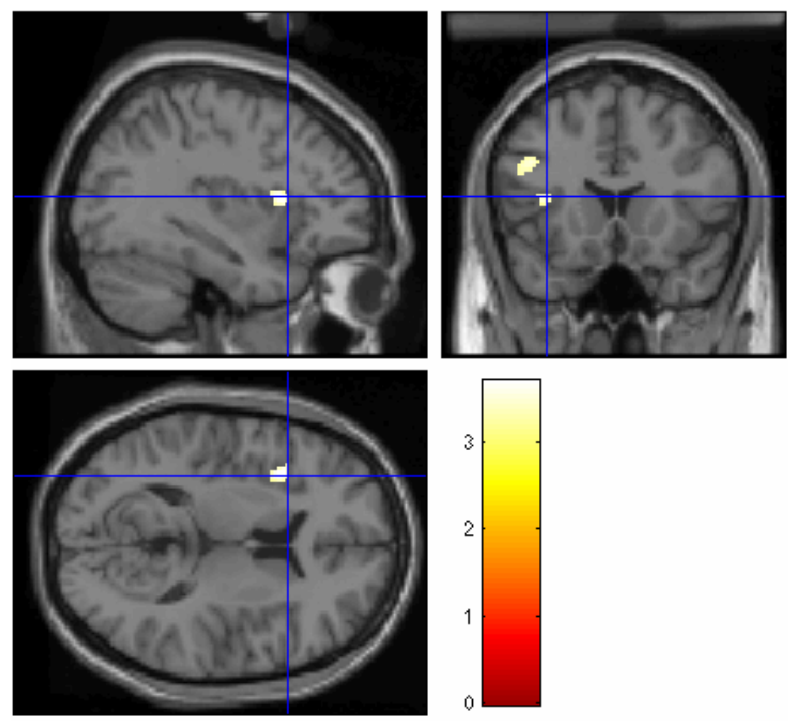

Figura 4. Doentes com esquizofrenia ativaram o opérculo frontal, ínsula anterior e giro frontal inferior esquerdo (correspondentes à área de Broca; p<0.001, sem correção) mais do que indivíduos saudáveis. Como a análise está corrigida para diferenças no desempenho da tarefa de fluência verbal, o resultado pode significar uma maior ineficiência fronto-cortical na esquizofrenia. (A escala colorida corresponde a valores do teste-T.)

A demonstração principal deste estudo foi a de que uma variação na COMT pode ter impacto na ativação durante a fluência verbal mas, ainda mais importante, que o efeito de um polimorfismo genético na função cerebral pode estar alterado no contexto da esquizofrenia. Na região em redor do sulco lateral direito (ou região Silviana direita) que compreende partes adjacentes do opérculo frontal e parietal e do giro temporal médio, o alelo Val158 teve um efeito na ativação em doentes, diferente daquele em indivíduos saudáveis, estando associado a maior ativação nos doentes e menor nos indivíduos saudáveis, relativamente ao Met158 (Figura 5). Por outras palavras, os homozigotas para o alelo Val158 (i.e. 
os indivíduos com duas cópias do alelo Val158, ou seja, aqueles com o genótipo Val158/Val158) ativaram mais esta região cerebral do que os homozigotas para o Met158 no grupo de doentes mas não no grupo de indivíduos saudáveis em que a tendência foi a oposta. Além disso, como era esperado de alelos codominantes, os heterozigotas (Met158/Val158, os seja, aqueles indivíduos com uma cópia de cada alelo) tiveram em geral uma ativação intermédia entre ambos os grupos heterozigotas. O Met158 também já foi previamente associado a uma maior ativação no hipocampo, amígdala cerebelosa, tálamo e córtex pré-frontal ventrolateral durante a apresentação visual de estímulos afectivos (Drabant et al., 2006; Smolka et al., 2005), mas o contrário tem-se verificado durante a memória de trabalho (Bertolino et al., 2006c; Bertolino et al., 2006b; Egan et al., 2001b) ou controlo da atenção (Blasi et al., 2005).
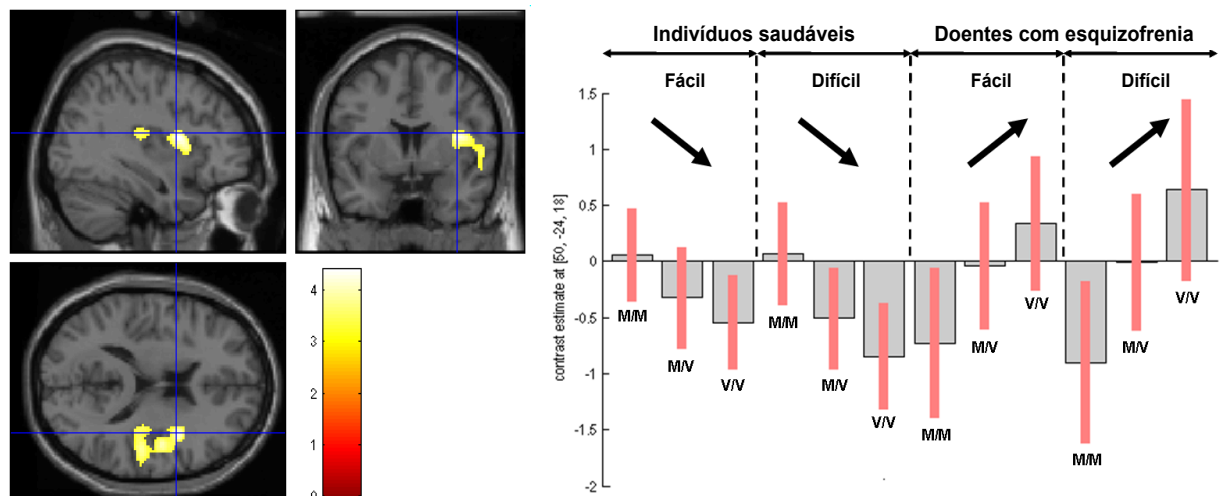

Figura 5. Interação diagnóstico x genótipo COMT Val18Met na ativação cerebral durante a fluência verbal. No opérculo frontal/ínsula anterior direita, opérculo parietal direito e giro temporal medio direito (i.e. região peri-Silviana), o alelo Val158 mostrou-se associado a uma menor ativação que o Met158 em indivíduos saudáveis, mas o inverso ocorreu nos doentes com esquizofrenia (FDR no cérebro inteiro $\mathrm{p}<0.05)$. O gráfico representa a ativação durante a geração de palavras subtraída à obtida durante a repetição de palavras num voxel do opérculo parietal direito (representativo de toda a região peri-Silviana) em cada grupo genotípico e diagnóstico e em dois graus de dificuldade da tarefa. É de notar que o efeito do genótipo em cada grupo foi o mesmo em ambas as versões de dificuldade da tarefa e que os heterozigotas mostraram um nível de ativação intermédio relativamente aos dois grupos homozigotas, como esperado sendo os alelos codominantes. (M=Met158; V=Val158) 
Esta diferença entre sujeitos saudáveis e doentes, em termos do efeito do COMTVal158Met, foi responsável por 13\% da variância inter-individual e é de particular interesse sendo que levanta a possibilidade de a distribuição de genótipos em amostras de doentes e indivíduos saudáveis poder influenciar o padrão de diferenças entre ambos os grupos diagnósticos, senão for tida em conta (2006b). Esta é também a primeira evidência de um efeito do COMTVal158Met em áreas temporais e insulares do cérebro, sendo que estudos prévios (usando o paradigma da memória de trabalho) apenas reportaram efeitos nos córtices pré-frontal, dorso lateral e cingulado (Bertolino et al., 2006c; Bertolino et al., 2006b; Bertolino et al., 2004; Egan et al., 2001b).

A ressonância magnética não pode medir diretamente os níveis de dopamina. No entanto, dado que a COMT metaboliza a dopamina cortical, diferenças nos efeitos da COMTVal158Met na ativação cerebral em doentes com esquizofrenia e indivíduos saudáveis podem estar plausivelmente relacionadas com a diferença entre ambos os grupos em termos de atividade dopaminérgica cerebral. A função dopaminérgica anormal é uma característica patofisiológica fundamental da esquizofrenia, havendo robusta evidência in vivo de uma acrescida libertação e disponibilidade sináptica de dopamina no estriado (revisto em Howes et al., 2007; Abi-Dargham, 2004). Esta hiperatividade dopaminérgica estriatal está efetivamente correlacionada com uma alterada ativação cortical durante tarefas cognitivo-executivas (Meyer-Lindenberg et al., 2002), sendo que também existe uma correlação negativa entre a função dopaminérgica no estriado e o desempenho neste tipo de tarefas cognitivas (em contraste com uma positiva em indivíduos saudáveis) (McGowan, Lawrence, Sales, Quested \& Grasby, 2004). Evidência indireta de estudos imagiológicos in vivo indica que tanto a esquizofrenia (Akil et al., 2003; Abi-Dargham et al., 2002), como o alelo Val158 da COMT em indivíduos saudáveis estão associados a uma redução de atividade dopaminérgica cortical (Slifstein et al., 2008), mesmo que não no mesmo grau.

Os inputs dopaminérgicos modulam a eficiência da função cortical, principalmente através dos receptores D1 (Slifstein et al., 2008; Goldman-Rakic, Muly, III \& Williams, 2000). Esta sintonização ('tuning') da função 
cortical pode ser representada numa curva em U-invertido (Figura 6), sendo que tanto dopamina a mais como a menos prejudica a função cortical, o que, comportamentalmente, pode manifestar-se numa desempenho inferior (Barnett, Scoriels \& Munafo, 2008) ou, fisiologicamente, numa atividade acrescida para o mesmo nível de desempenho (i.e. uma menor eficiência) (Barnett et al., 2008; Goldman-Rakic et al., 2000).

Para procurar encontrar a razão pela qual observámos este efeito na área peri-Silviana direita e não, como seria mais esperado, na homóloga esquerda (que inclui a área de Broca) mais crítica para a fluência verbal, realizámos uma análise de conectividade funcional. Esta consistiu numa busca por todo o cérebro de regiões cuja ativação estivesse temporalmente correlacionada com a nossa região de referência, a per-Sliviana direita. A região que encontrámos foi justamente a área de Broca, i.e. o opérculo frontal, ínsula anterior e giro frontal inferior esquerdos. Esta correlação também se mostrou dependente tanto do genótipo para Val15Met como do diagnóstico. Nos doentes, a conectividade entre as regiões foi mais forte em homozigotas para o Val158 do que homozigotas para o Met158 (sendo, mais uma vez, intermédia para os heterozigotas), enquanto nos indivíduos saudáveis, o inverso se verificou $(\mathrm{p}<0.001$, sem correção). O efeito desta interação foi responsável por $20 \%$ da variância inter-individual na ativação da insula anterior. Além de ser uma região crítica para a fluência verbal foi também justamente aquela na qual havíamos verificado uma ativação exagerada nos doentes. Isto sugere que a diferença em termos de efeitos da COMT entre doentes e indivíduos saudáveis pode dever-se ao maior recrutamento da área de Broca nos doentes, que altera assim a sua influência na região homóloga (direita). Alternativamente, este maior recrutamento pode refletir a necessidade de uma maior ativação local de modo a produzir a mesma resposta no hemisfério direito (Weinberger, Berman \& Chase, 1988a), dado que a conectividade entre os hemisférios é anormalmente elevada na esquizofrenia (Friston et al., 1995). Tal conectividade comprometida na esquizofrenia é também passível de ser susceptível a um efeito genético (do COMT Val158Met).

Em conclusão, estes dados sugerem que o efeito do polimorfismo Val158Met do gene para a COMT - enzima metabolizadora da dopamina 
- na função cerebral durante uma tarefa executiva é diferente em doentes com esquizofrenia e indivíduos saudáveis. Tal efeito contrastante detectado na região peri-Silviana pode ser devido a uma reduzida atividade dopaminérgica nesta região em esquizofrenia e/ou na área englobando o opérculo frontal e ínsula anterior esquerdos (área de Broca) que se mostrou mais ativo em doentes do quem indivíduos saudáveis durante a tarefa. Isto pode refletir a alterada função dopaminérgica típica da esquizofrenia, que por sua vez pode advir de outros factores provenientes ou causais (genéticos ou ambientais) da doença.

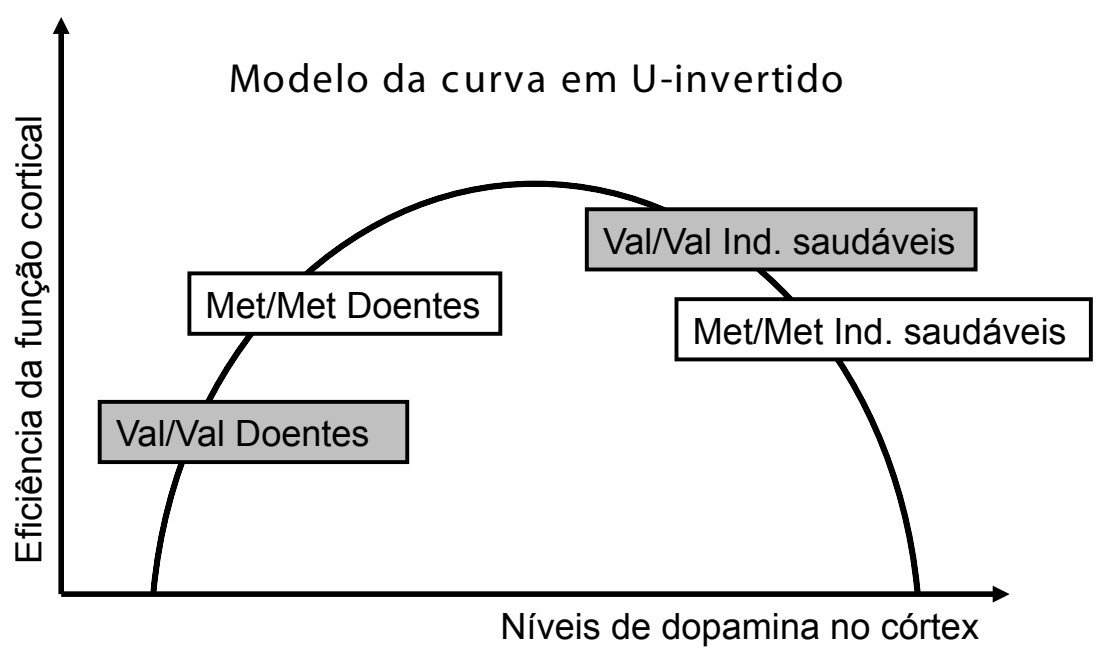

Figura 6. Relação putativa entre a atividade dopaminérgica aferente no córtex (eixo x) e eficiência da função cortical (eixo y) (Abi-Dargham et al., 2002). Segundo este modelo, devido à decrescida função cortical dopaminérgica na esquizofrenia, os doentes ficariam situados no lado esquerdo do vértice desta curva, sendo que, entre eles, os homozigotas para Met158 (os quais metabolizam a dopamina menos eficazmente) têm níveis de dopamina mais perto do ótimo comparados com os homozigotas para Val158 (que por isso ficariam na extrema esquerda). Os indivíduos saudáveis, em que a atividade dopaminérgica cortical não está demasiado reduzida, estariam à direita do vértice da curva. Ao limitar (contrariar) os efeitos nocivos de uma 'sobrecarga' de dopamina que levaria a um rácio sinal: ruído menor, é possível que os indivíduos saudáveis homozigotas para Val158 tenham um nível de atividade dopaminérgica cortical mais próximo do ótimo em termos de eficiência cortical do que homozigotas para Met158, e do que doentes com ambos os genótipos. 


\subsubsection{Efeito do DAT - Incluído em Prata et al. Altered effect of dopamine transporter 3'UTR VNTR genotype on pre frontal and striatal function in schizophrenia. Arch.Gen.Psychiatry, 2009 Nov; 66 (11): 1162-72. (Prata et al., 2009b)}

O transportador pré-sináptico da dopamina (dopaminetransporter, DAT; SLC6A3) tem um papel fundamental na regulação da dopamina central dada a sua mediação da recaptação de dopamina do espaço sináptico para o neurónio dopaminérgico pré-sináptico (Masson et al., 1999). A sua expressão é mais alta nos neurónios do estriado, substantianigra e área tegumental ventral (Sesack \& Carr, 2002; Lewis et al., 2001; Ciliax et al., 1995), embora também seja abundante no tálamo e nos córtices insular, motor, parietal posterior e cingulado posterior (Lewis et al., 2001; Wang et al., 1995). É expresso em menor grau nos córtices pré-frontal, cingulado anterior, sensorial primário e occipital (Lewis et al., 2001; Sesack, Hawrylak, Guido \& Levey, 1998; Wang et al., 1995) sendo que a taxa de recaptação de dopamina nestas regiões é relativamente baixa (Wayment, Schenk \& Sorg, 2001). Nestas regiões com níveis baixos de DAT, a degradação intracelular da dopamina pela COMT, e a captação por transportadores não específicos tais como o transportador da noradrenalina (NET) podem ter um papel relativamente maior na regulação da disponibilidade sináptica local da dopamina. Nestas regiões o DAT é também principalmente extra-sináptico (mais do que intra-sináptico) e pode regular antes o transbordo ('spill-over') de dopamina para o espaço extra-sináptico (Bertolino et al., 2006a; Tunbridge et al., 2006; Cragg \& Rice, 2004). O gene humano para o DAT contém um polimorfismo de 40 pares de bases (bp) ('variable number of tandem repeats' ou VNTR) na região 3' não-traduzida (3 'untranslated region' ou DAT 3'UTR VNTR). Isto leva à existência de vários alelos que têm desde 3 a 11 cópias da sequência de $40 \mathrm{bp}$, sendo os de 9 e os de 10 cópias os mais comuns (Vandenbergh et $a l ., 1992)$. Embora este polimorfismo não afecte a estrutura da proteína (Vandenbergh et al., 2000), pode influenciar a transcrição (de ADN para mARN, i.e, ácido ribonucleico mensageiro). Quatro estudos independentes (VanNess, Owens \& Kilts, 2005; Mill, Asherson, Browes, D'Souza \& Craig, 
2002; Fuke et al., 2001; Heinz et al., 2000) descobriram que o alelo 10 estava associado a uma maior expressão do DAT, embora tenha havido um estudo que encontrou níveis mais baixos de expressão (van Dyck et al., 2005) e outro que não encontrou associação (Martinez et al., 2001). Este polimorfismo também já foi associado à doença de Parkinson's (Le Couteur, Leighton, McCann \& Pond, 1997), ao alcoolismo (Muramatsu \& Higuchi, 1995), ao défice de atenção e hiperatividade (Faraone et al., 2005; Gill, Daly, Heron, Hawi \& Fitzgerald, 1997) e ao síndroma de Tourette (Diaz-Anzaldua et al., 2004; Comings et al., 1996). Estudos prévios de imagiologia funcional usando paradigmas de memória em indivíduos saudáveis também já reportaram um efeito do DAT 3'UTR VNTR na ativação pré-frontal e uma interação entre este efeito e o do COMT Val158Met na mesma região (Bertolino et al., 2008; Caldu et al., 2007; Yacubian et al., 2007; Bertolino et al., 2006a). Esta interação também já foi identificada na ativação do hipocampo e do estriado durante tarefas de memória e de recompensa, respectivamente (Bertolino et al., 2008).

Tal como para a COMT Val158Met no estudo acima, usámos imagiologia de ressonância magnética para examinar a influência do DAT 3'UTR VNTR na ativação cerebral regional durante uma tarefa de fluência verbal e para avaliar até que ponto esta pode estar alterada na esquizofrenia devido ao seu característico desequilíbrio dopaminérgico. Porque expressam níveis mais altos de DAT (Sesack et al., 2002; Lewis et al., 2001; Wang et al., 1995; Ciliax et al., 1995), e estão fundamentalmente envolvidos na fluência verbal (Fu et al., 2002; Curtis et al., 1998), nós previmos que DAT 3'UTR VNTR modularia ativação no estriado, tálamo e ínsula e, de acordo com isso, restringimos esta análise à rede de áreas do cérebro significativamente mais ativadas durante a geração de palavras (após subtração da ativação durante a repetição de palavras). A nossa segunda hipótese é que este polimorfismo tem um efeito diferente em doentes com esquizofrenia e indivíduos saudáveis em duas áreas em que há boa evidência de que a função dopaminérgica está perturbada na esquizofrenia: o estriado (Meyer-Lindenberg et al., 2002; Bertolino et al., 2000; Grace, 2000; Laruelle, 2000) e o córtex pré-frontal dorso lateral (Abi-Dargham et al., 2003; Akil et al., 1999; Weinberger, Berman \& Chase, 1988b). Embora 
este último não expresse níveis muito altos de DAT está conectado ao estriado através do circuito córtico-talâmico-estriatal (Caldu et al., 2007; Bertolino et al., 2006a), e já foi reportado que esta variação no DAT influencia a ativação em ambas as áreas (Caldu et al., 2007; Yacubian et al., 2007). Adicionalmente, o córtex pré-frontal é uma área onde já se demonstrou robustamente uma alterada ativação na esquizofrenia durante a fluência verbal e outras tarefas cognitivas (Abi-Dargham et al., 2003; Akil et al., 1999; Weinberger et al., 1988b). De acordo com esta hipótese, restringimos esta análise a coordenadas do estriado e do córtex pré-frontal em que um efeito deste polimorfismo foi encontrado em estudos prévios independentes (Caldu et al., 2007; Yacubian et al., 2007).

A nossa hipótese de que uma variação no DAT influenciaria a ativação especificamente relacionada com a fluência verbal foi confirmada na ínsula esquerda e no núcleo caudato (parte do estriado). Em ambas estas regiões, o alelo 10 esteve associado a uma maior ativação do que o alelo 9 em ambos os indivíduos saudáveis e doentes (Figura 6). Tal pode ser interpretado em termos de efeitos da dopamina na eficiência da função cortical. De acordo com este modelo, o alelo 10 favorece a produção de mais DAT do que o alelo 9 e portanto a remoção mais rápida de dopamina da sinapse, reduzindo-a para um nível sub-ótimo em termos da eficiência da função cortical o que leva à híper-ativação (Abi-Dargham et al., 2003; Akil et al., 1999; Weinberger et al., 1988b). Esta é a primeira evidência de um efeito de um polimorfismo no DAT na função da ínsula em humanos, sendo que o mesmo efeito já tem sido reportado no hipocampo (em interação com a COMT Val158Met) e no córtex pré-frontal (Bertolino et al., 2008; Caldu et al., 2007; Bertolino et al., 2006a). O núcleo caudato é um local de terminação das projeções dopaminérgicas centrais provenientes do tronco cerebral (Lindvall \& Bjorklund, 1978). O grau até ao qual o modelo de 'sintonização' dopaminérgica da eficiência cortical (curva em U-invertido) é aplicável ao estriado ainda não é claro.

Verificou-se uma tendência para o alelo 10 estar associado a uma maior desativação durante a geração de palavras comparado com o alelo 9 no córtex cingulado anterior rostral (Figura 7). O envolvimento relativamente maior desta região durante a repetição verbal de palavras (em contraste 
com a geração) pode estar relacionado com o seu envolvimento na rede basal ('default network') que medeia processos internamente gerados durante condições base ('low level baseline conditions') (McKiernan et al., 2006; Binder et al., 1999). A direção do efeito do DAT 3'UTR VNTR's na ativação do cingulado é a mesma que a de um estudo prévio, embora este tenha sido numa parte mais dorsal do cingulado durante a memória de trabalho (Bertolino et al., 2006a).

Consistentemente com a nossa hipótese de uma interação entre genótipo e diagnóstico, detectamos uma no giro frontal medio esquerdo (Figura 8). Nesta região houve uma ativação significativamente maior nos doentes com o alelo 9 do que os doentes homozigotas para o alelo 10, mas uma resposta semelhante nos dois grupos genótipos saudáveis. O facto deste efeito do genótipo ser evidente em doentes com esquizofrenia, sendo responsável por mais do que um quinto da variância inter-individual (21.5\%), mas não em indivíduos saudáveis, levanta a possibilidade de que o efeito do alelo 9 interage com outros factores que contribuem para a perturbação da função dopaminérgica na doença. Pensa-se que na esquizofrenia a atividade dopaminérgica está aumentada no estriado mas decrescida no córtex (Laruelle \& Abi-Dargham, 1999; Laruelle, bi-Dargham, Gil, Kegeles \& Innis, 1999; Abi-Dargham et al., 1998; Breier et al., 1997). O DAT está presente em níveis relativamente baixos no córtex pré-frontal mas é abundante no estriado (Lewis et al., 2001; Ciliax et al., 1995) e portanto os efeitos que observamos no córtex pré-frontal podem ser secundários aos efeitos do DAT no estriado. O estriado recebe input dopaminérgico da substantianigra e da área tegumental ventral e o DAT remove a dopamina do espaço intra-sináptico nestes terminais, reduzindo a estimulação dos receptores da dopamina que no estriado são predominantemente D2 (Sesack \& Pickel, 1992; Camps, Cortes, Gueye, Probst \& Palacios, 1989; Cortes, Gueye, Pazos, Probst \& Palacios, 1989). A estimulação destes receptores leva a efeitos inibitórios no tálamo, que projeta até ao córtex pré-frontal. Um decréscimo na atividade do DAT associado ao alelo 9 pode portanto aumentar os níveis dopaminérgicos sinápticos e, como consequência, a estimulação D2 no estriado, inibindo o tálamo e decrescendo o input excitatório no córtex pré-frontal que 
pode diminuir demasiado o rácio sinal: ruído ('signal-to-noise') e assim afastá-lo do ótimo, nesta área. Na esquizofrenia, é possível que uma atividade dopaminérgica aumentada no estriado esteja a ser amplificada nos doentes com o alelo 9 (que permite maior abundância de dopamina intra-sináptica no estriado), o que pode aumentar ainda mais os níveis de dopamina e a inibição no tálamo, levando a uma marcada redução do rácio sinal: ruído nos neurónios piramidais pré-frontais (Tanaka, 2006). Tal pode ser responsável pela acrescida ativação pré-frontal que detectamos em doentes.

a)
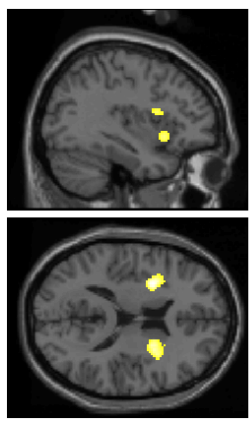

b)
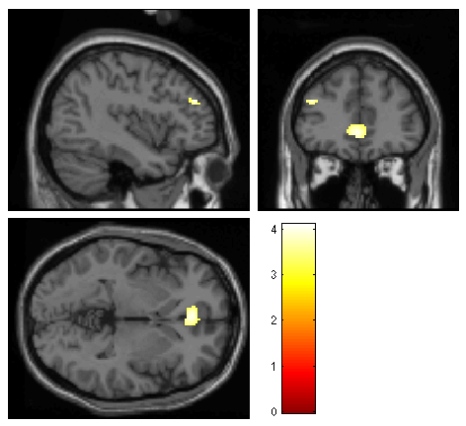

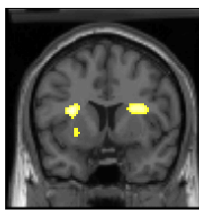

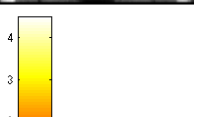
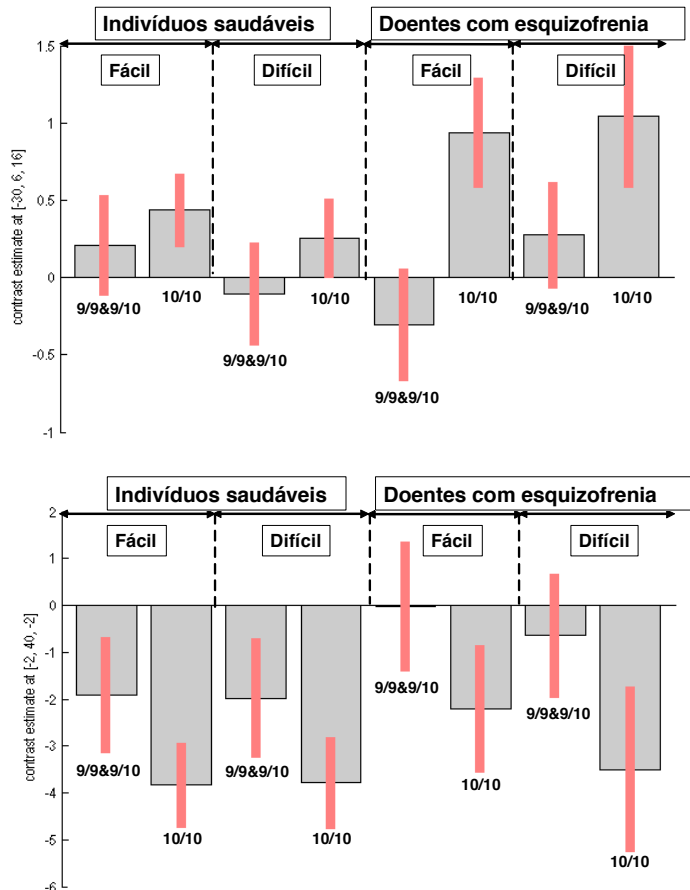

Figura 7. Efeito principal de um polimorfismo no gene codificador do transportador da dopamina (DAT 3'UTR VNTR) na ativação cerebral durante a geração relativamente à repetição de palavras. a) Homozigotas para o alelo 10 mostraram maior ativação na ínsula esquerda (no gráfico), no núcleo caudato direito (correção para volume restrito FWEp< 0.05$)$ e na ínsula direita $(\mathrm{p}<0.001$, sem correção) durante a geração de palavras do que os portadores do alelo 9. b) No giro cingulado anterior, os homozigotas para o alelo 10 mostraram maior desativação durante a geração de palavras que os portadores do alelo $9(\mathrm{p}<0.001$, sem correção). 
Uma interação semelhante foi evidente no núcleo acumbente esquerdo (Figura 8). Nos indivíduos saudáveis, esta região esteve mais ativa durante a repetição do que a geração verbal nos portadores do alelo 9, no entanto não houve diferença entre as fases da tarefa nos homozigotas para o alelo 10. O inverso aconteceu nos doentes. Como discutido em relação à interação no córtex pré-frontal, na esquizofrenia, a atividade dopaminérgica acrescida no estriado pode alterar o impacto da variação no DAT nos níveis locais de dopamina, produzindo o efeito oposto na ativação em doentes (em comparação com os indivíduos saudáveis).

a)
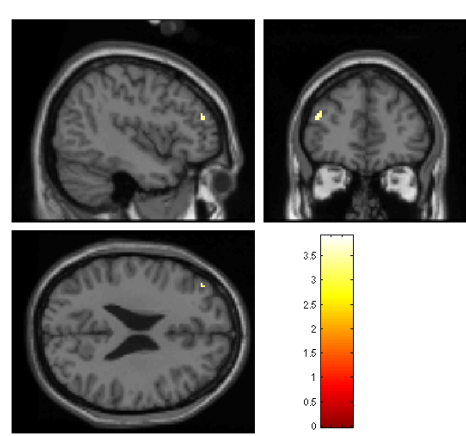

b)
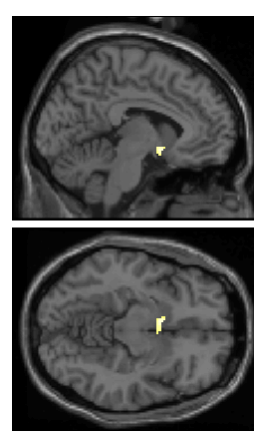
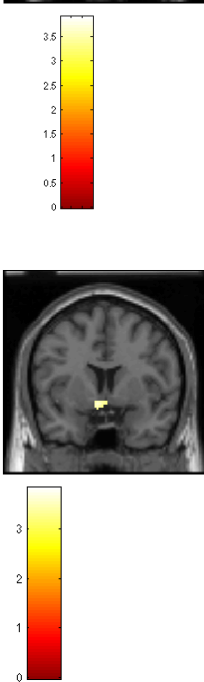
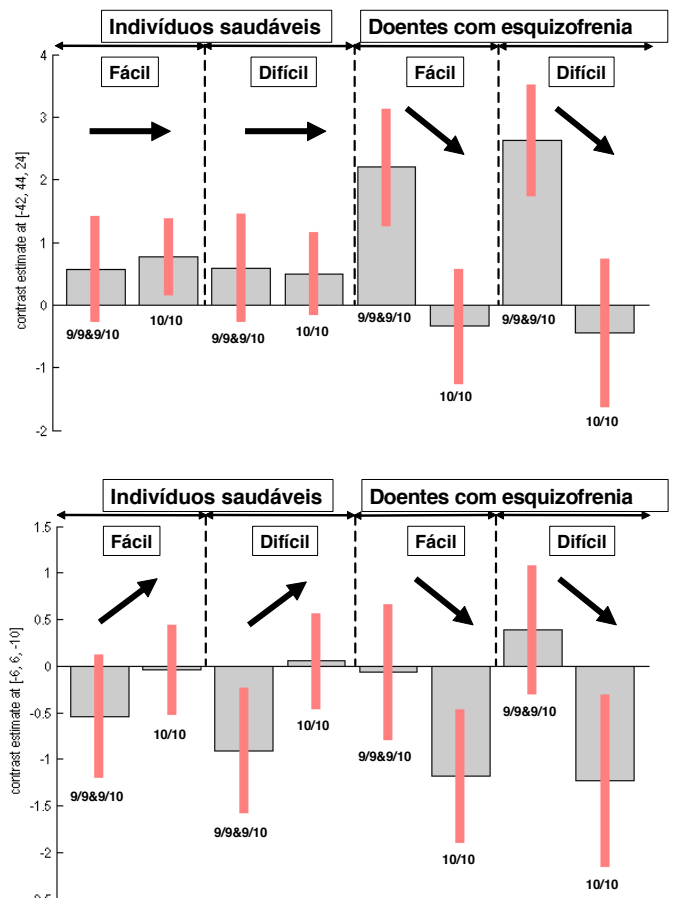

Figura 8. Interação entre o efeito de diagnóstico e o do DAT 3'UTR VNTR na ativação durante a geração relativamente à repetição de palavras no giro frontal médio esquerdo (a) e no estriado ventral esquerdo (núcleo acumbente) (b). O efeito do genótipo em indivíduos saudáveis foi significativamente diferente daquele nos doentes com esquizofrenia (correção para volume restrito FWEp<0.05). 
Em conclusão, estes dados sugerem que o efeito da variação no gene para o DAT, na função cerebral regional durante processos executivos é diferente em doentes com esquizofrenia comparados com indivíduos saudáveis e que tal pode refletir a função dopaminérgica alterada na esquizofrenia.

\subsubsection{Efeito da interação DAT x COMT - Incluído em Prata D. P. et} al. Epistasis between the DAT 3' UTR VNTR and the COMT Val158Met SNP on cortical function in healthy subjects and patients with schizophrenia. Proc.Natl.Acad.Sci. U S A., 2009 Aug 11; 106 (32): 13600-5. (Prata et al., 2009a)

Também investigámos se haveria epístase (i.e. interação) entre DAT 3'UTR VNTR e COMT Val158Met na função cortical na mesma amostra de indivíduos saudáveis e doentes com esquizofrenia e com os mesmos dados imagiológicos usados acima (i.e. para a fluência verbal) (Tanaka, 2006). Em suma, houve uma interação entre ambos os polimorfismos na ativação do giro supramarginal esquerdo independentemente do grupo diagnóstico bem como no grupo de indivíduos saudáveis. Nesta região, uma ativação relativamente maior foi detectada apenas quando os homozigotas para Met158 da COMT também possuíam o alelo 9 do DAT, ou, em reverso, quando os homozigotas para o Val158 também o eram para o alelo 10. Além disso, houve uma significativa interação diagnóstico $x$ COMT x DAT no giro orbital direito, onde, apenas em doentes, uma maior ativação estava associada à co-ocorrência dos alelos 9 e Val158 e à co-ocorrência dos alelos 10 e Met158. Estes dados demonstram que os genes COMT e DAT interagem não aditivamente para modular a função cortical durante processos executivos e além disso que este efeito está significativamente alterado na esquizofrenia, o que, embora ainda não seja claro como, pode, mais uma vez, refletir a função dopaminérgica anormal na doença. 
1.1.4. Efeito do DISC1 - Incluído em Prata D. P. et al. Effect of disrupted-in-schizophrenia-1 on pre-frontal cortical function. Mol Psychiatry2008 Oct; 13(10): 915-7, 909. (Prata et al., 2008) e Prata D. P. et al. No association of Disrupted-in-Schizophrenia-1 variation with prefrontal function in patients with schizophrenia and bipolar disorder. Genes Brain Bebav., 2011 Apr; 10(3): 276-85. (Prata et al., 2011)

Vários estudos de linkage e associação genética têm implicado o gene Disrupted-in-Schizophrenia-1 (DISC1) na susceptibilidade para a esquizofrenia e doença bipolar (Porteous, Thomson, Brandon \& Millar, 2006) mas relativamente pouco se sabe do seu efeito na função cerebral. A proteína DISC1 é expressa nos centrossomas, mitocôndrias, citoplasma das dendrites pós-sinápticas e nas fibras-stress de actina dos neurónios corticais (Porteous et al., 2006). Interage com proteínas envolvidas na divisão celular, organização do transporte intracelular, incluindo a PDE4B, que está ligada à aprendizagem e memória e a Ndel1, uma reguladora-chave na migração neuronal e um alvo putativo da ação dos antipsicóticos (Porteous et al., 2006). Um knock-down do gene DISC1 perturba o crescimento axonal in vitro (Porteous et al., 2006) e a migração neuronal cortical e arborização dendrítica in vivo (Porteous et al., 2006). Sobre-expressão do DISC1 leva a um maior crescimento axonal in vitro (Porteous et al., 2006), enquanto a expressão de DISC1 humano mutante em ratos está associado a anomalias comportamentais, alargamento ventricular e atenuação do crescimento axonal (Porteous et al., 2006).

Testámos a hipótese de que uma variação neste gene de risco para a esquizofrenia (e doença bipolar) teria um impacto na função cerebral durante a fluência verbal, usando fMRI. Selecionámos o polimorfismo Ser704Cys codificado pelo SNP rs821616 porque, dos polimorfismos não-sinónimos (que se traduzem numa mudança na cadeia de aminoácidos), este é o único na DISC1 até à data a ter demonstrado um impacto funcional ao nível molecular (Gur, Keshavan \& Lawrie, 2007). Além disso, em estudos de associação genética, o Ser704Cys também está associado à susceptibilidade para a esquizofrenia (Hashimoto et al., 
2006). Estudos de neuroimagiologia também sugerem que tem efeitos na estrutura ou função de regiões cerebrais que estão implicadas nas doenças psicóticas tais como a matéria branca frontal (Callicott et al., 2005), o giro cingulado anterior (Hashimoto et al., 2006), e o hipocampo (Hashimoto et al., 2006).

Nos indivíduos saudáveis, observámos que tanto os homozigotas para o Ser704 como os portadores do Cys704 mostraram ativação bilateral no córtex pré-frontal durante a fluência verbal com maior envolvimento do hemisfério esquerdo do que o direito (Figura 9). No entanto a ativação dos homozigotas para o Ser704 foi significativamente maior que a dos portadores do Cys704, particularmente nos giros frontais superiores e médios esquerdos. No voxel onde o efeito foi máximo, o genótipo foi responsável por $13 \%$ da variância inter-individual. Diferenças adicionais foram evidentes na parte homóloga do giro frontal superior no hemisfério direito e no córtex frontal inferior e cingulado, tálamo e núcleo caudato esquerdos. Não houve áreas significativamente mais ativadas nos transmissores do Cys704 do que nos sujeitos homozigotas para o Ser704.

a)
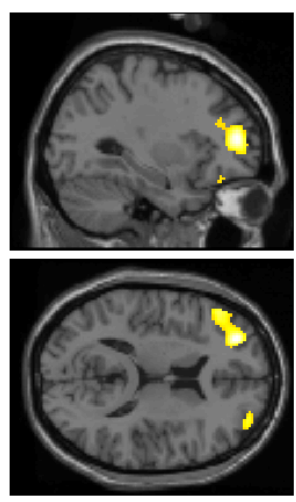
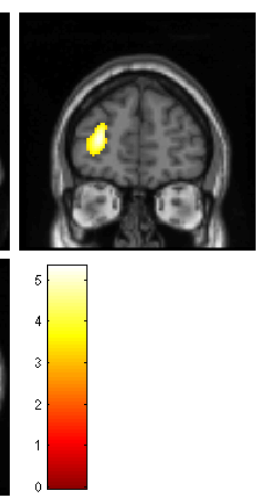

b)

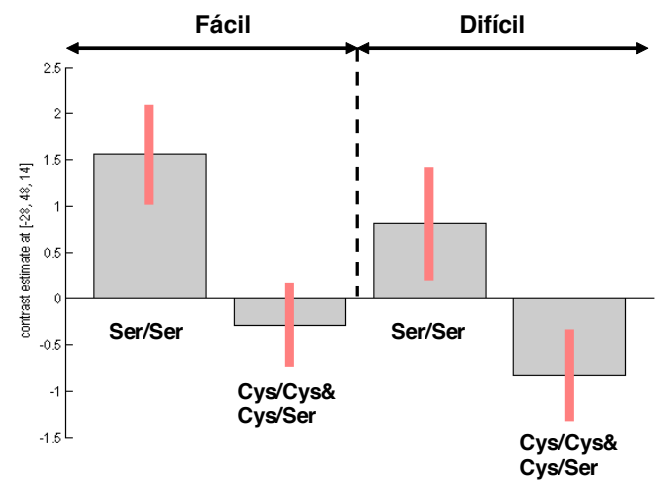

Figura 9. Efeito do polimorfismo DISC1 Ser704Cys na função pré-frontal de indivíduos saudáveis. Homozigotas para o Ser704 mostraram maior ativação durante a tarefa de fluência verbal do que os portadores do Cys704 no córtex pré-frontal, particularmente no hemisfério esquerdo (correção para o cérebro inteiro FDR $\mathrm{p}<0.05$ ). Este efeito foi independente da dificuldade da tarefa, sendo evidente tanto na versão fácil como na difícil. 
A maior ativação pré-frontal nos homozigotas para o Ser704 num contexto de um nível de desempenho igual pode ser interpretado como uma manifestação de uma função pré-frontal menos eficiente, sendo que é precisa mais ativação para chegar ao mesmo resultado comportamental. (Cannon et al., 2005) Isto é consistente com a associação do Ser704 a um maior risco para a esquizofrenia (Winterer \& Weinberger, 2004) e a uma memória declarativa deficitária em esquizofrenia (Callicott et al., 2005). O polimorfismo Ser704Cys já fora associado a alterações no volume do cingulado anterior (Callicott et al., 2005), à integridade da matéria branca frontal (Hashimoto et al., 2006) e à estrutura e à função do hipocampo (Hashimoto et al., 2006). No entanto, enquanto os efeitos do hipocampo foram na mesma direção do que se observa no risco para a esquizofrenia, o oposto se verificou para os efeitos no volume do cingulado e integridade da matéria branca frontal. O presente estudo também detectou efeitos do Ser704Cys na ativação de regiões além do córtex pré-frontal, incluindo o córtex cingulado, o estriado e o tálamo. Tal como o Ser704Cys, outros polimorfismos na DISC1 podem afectar a função cerebral; de facto, haplótipos no DISC1 (Callicott et al., 2005) e o Leu607Phe (rs6675281) (Cannon et al., 2005) também já foram associados a alterações no volume e densidade da matéria cinzenta no córtex pré-frontal. Em suma, apresentamos a primeira evidência de que a DISC1 modula a função pré-frontal em humanos. Isto é consistente com o papel crítico desta região na patofisiologia das doenças psicóticas e com observações prévias que tornaram este gene um factor de risco dos mais robustos na esquizofrenia e na doença bipolar.

Em doentes com esquizofrenia ou doença bipolar, não foi detectado qualquer efeito significativo do DISC1 Ser704Cys. No entanto, quando os indivíduos saudáveis foram contrastados com doentes com esquizofrenia, houve uma interação genótipo $\mathrm{x}$ diagnóstico numa das áreas em que se detectou um efeito em indivíduos saudáveis: o giro frontal médio e superior esquerdo (correção em volume restrito FWE p=0.002). Nesta região, a tendência (não estatisticamente significativa) nos doentes foi contrária à observada nos indivíduos saudáveis: os doentes portadores do Cys704 ativaram mais que os doentes homozigotas para Ser704. A ausência de 
um efeito significativo em doentes pode refletir interações dos efeitos deste polimorfismo na DISC1com os efeitos de variações noutros genes associados com estas doenças e/ou com as consequências das próprias doenças na função cerebral.

\subsection{Implicações}

Os resultados dos estudos apresentados podem ter implicações relevantes na investigação corrente da função cerebral ou do papel de genes comportamentais na população saudável e na esquizofrenia. Eles providenciam a primeira evidência de que:

1) O mesmo polimorfismo genético pode ter efeitos opostos em regiões diferentes do cérebro. Por exemplo, no córtex pré-frontal, a direção alélica do efeito do DAT foi oposta ao da ínsula, possivelmente refletindo diferenças em termos do grau de expressão média (irrespectivamente do genótipo) do DAT entre regiões do cérebro (Lewis et al., 2001; Sesack et al., 1998; Wang et al., 1995);

2) Os genes reguladores da dopamina interagem não-aditivamente para modular a função cerebral cortical. Dado que estes genes regulam a disponibilidade sináptica da dopamina nas mesmas vias neurais, é plausível que o seu impacto seja intrinsecamente interdependente, especialmente em áreas corticais onde ambos são bastante expressos;

3) A fluência verbal é um paradigma útil para investigar os efeitos de genes reguladores da dopamina em conjunto com a neuroimagiologia funcional. A tarefa envolve várias regiões do cérebro que têm um input dopaminérgico substancial incluíndo o estriado, o tálamo e os córtices pré-frontal, cingulado e insular. A maioria dos estudos prévios endofenotípicos da esquizofrenia têm utilizado outros paradigmas de memória de trabalho que recrutam significativamente o córtex pré-frontal mas não a ínsula. O presente paradigma foi capaz de revelar um efeito de DAT, COMT e DISC1, individualmente, na ínsula; 
4) O efeito de um gene na função cerebral pode ser diferente num contexto clínico, como a esquizofrenia. Por outras palavras, interações entre o efeito de um determinado variante genético e o efeito da doença no cérebro podem ser frequentes. Por exemplo, o alelo Val158 da COMT mostrou estar associado a uma maior ativação da área cortical peri-Silviana durante a fluência verbal em contraste com Met158 mas apenas em doentes com esquizofrenia, enquanto o oposto de verificou em indivíduos saudáveis.

\section{Referências bibliográficas}

ABI-DARgham, A. (2004). Do we still believe in the dopamine hypothesis? New data bring new evidence. Int.J Neuropsychopharmacol., 7 Suppl 1, S1-S5.

Abi-Dargham, A., Gil, R., Krystal, J., BAldwin, R. M., Seibyl, J. P., Bowers, M. et al. (1998). Increased striatal dopamine transmission in schizophrenia: confirmation in a second cohort. Am J Psychiatry, 155, 761-767.

Abi-Dargham, A., Mawlawi, O., lombardo, I., Gil, R., Martinez, D., HuAng, Y. et al. (2002). Prefrontal dopamine D1 receptors and working memory in schizophrenia. J.Neurosci., 22, 3708-3719.

ABI-DARgham, A. \& MOORE, H. (2003). Prefrontal DA transmission at D1 receptors and the pathology of schizophrenia. Neuroscientist., 9, 404-416.

AKil, M., Kolachana, B. S., Rothmond, D. A., Hyde, T. M., Weinberger, D. R. \& KleinMAN, J. E. (2003). Catechol-O-methyltransferase genotype and dopamine regulation in the human brain. J.Neurosci., 23, 2008-2013.

AKil, M., Pierri, J. N., Whitehead, R. E., Edgar, C. L., Mohila, C., SAmpson, A. R. et al. (1999). Lamina-specific alterations in the dopamine innervation of the prefrontal cortex in schizophrenic subjects. Am.J.Psychiatry, 156, 1580-1589.

Aukes, M. F., Alizadeh, B. Z., Sitskoorn, M. M., Selten, J. P., Sinke, R. J., Kemner, C. et al. (2008). Finding Suitable Phenotypes for Genetic Studies of Schizophrenia: Heritability and Segregation Analysis. Biological Psychiatry, In Press, Corrected Proof.

BARNETT, J. H., SCORIEls, L. \& MUNAFO, M. R. (2008). Meta-Analysis of the Cognitive Effects of the Catechol-O-Methyltransferase Gene Val158/108Met Polymorphism. Biol. Psychiatry.

Bertolino, A., Blasi, G., latorre, V., Rubino, V., RAMPino, A., Sinibaldi, L. et al. (2006a). Additive effects of genetic variation in dopamine regulating genes on working memory cortical activity in human brain. J.Neurosci., 26, 3918-3922.

Bertolino, A., Breier, A., Callicott, J. H., Adler, C., Mattay, V. S., Shapiro, M. et al. (2000). The relationship between dorsolateral prefrontal neuronal $\mathrm{N}$-acetylaspartate and evoked release of striatal dopamine in schizophrenia. Neuropsychopharmacology, 22, 125-132.

Bertolino, A., Caforio, G., Blasi, G., De, C. M., Latorre, V., Petruzzella, V. et al. (2004). Interaction of COMT (Val(108/158)Met) genotype and olanzapine treatment on 
prefrontal cortical function in patients with schizophrenia. Am.J.Psychiatry, 161, 1798-1805.

Bertolino, A., Caforio, G., Petruzzella, V., Latorre, V., Rubino, V., Dimalta, S. et al. (2006b). Prefrontal dysfunction in schizophrenia controlling for COMT Val158Met genotype and working memory performance. Psychiatry Res., 147, 221-226.

Bertolino, A., Di, G. A., Blasi, G., SAmbataro, F., CAForio, G., Sinibaldi, L. et al. (2008). Epistasis between dopamine regulating genes identifies a nonlinear response of the human hippocampus during memory tasks. Biol.Psychiatry, 64, 226-234.

Bertolino, A., Rubino, V., SAmbataro, F., Blasi, G., latorre, V., FAZio, L. et al. (2006c). Prefrontal-hippocampal coupling during memory processing is modulated by COMT val158met genotype. Biol.Psychiatry, 60, 1250-1258.

Binder, J. R., Frost, J. A., Hammeke, T. A., Bellgowan, P. S., RaO, S. M. \& CoX, R. W. (1999). Conceptual processing during the conscious resting state. A functional MRI study. J Cogn Neurosci., 11, 80-95.

Blasi, G., MatTay, V. S., Bertolino, A., Elvevag, B., CAllicotT, J. H., DAs, S. et al. (2005). Effect of catechol-O-methyltransferase val158met genotype on attentional control. J.Neurosci., 25, 5038-5045.

BOKAT, C. E. \& GOLDBERG, T. E. (2003). Letter and category fluency in schizophrenic patients: a meta-analysis. Schizophrenia Research, 64, 73-78.

Bookheimer, S. Y., Strojwas, M. H., Cohen, M. S., SAunders, A. M., PericaK-VANCe, M. A., MAzziotTA, J. C. et al. (2000). Patterns of brain activation in people at risk for Alzheimer's disease. N.Engl.J Med, 343, 450-456.

Breier, A., SU, T. P., SAUnders, R., Carson, R. E., Kolachana, B. S., De, B. A. et al. (1997). Schizophrenia is associated with elevated amphetamine-induced synaptic dopamine concentrations: evidence from a novel positron emission tomography method. Proc. Natl.Acad.Sci.U.S.A, 94, 2569-2574.

Broome, M., Matthiasson, P., Fusar-Poli, P., Woolley, J., Johns, L., TABraham, P. et al. (2008). Neural correlates of executive function and working memory in the 'at-risk mental state'. British J Psychiatry (In Press).

Buckholtz, J. W., CAllicotT, J. H., Kolachana, B., Hariri, A. R., GOldberG, T. E., GeNDERSON, M. et al. (2008). Genetic variation in MAOA modulates ventromedial prefrontal circuitry mediating individual differences in human personality. Mol.Psychiatry, 13, 313-324.

Buckholtz, J. W., Meyer-Lindenberg, A., Honea, R. A., Straub, R. E., Pezawas, L., Egan, M. F. et al. (2007). Allelic variation in RGS4 impacts functional and structural connectivity in the human brain. $J$ Neurosci., 27, 1584-1593.

Caldu, X., Vendrell, P., Bartres-Faz, D., Clemente, I., Bargallo, N., Jurado, M. A. et al. (2007). Impact of the COMT Val108/158 Met and DAT genotypes on prefrontal function in healthy subjects. Neuroimage., 37, 1437-1444.

CallicotT, J. H., Bertolino, A., MatTay, V. S., LANGheim, F. J., Duyn, J., Coppola, R. et al. (2000). Physiological dysfunction of the dorsolateral prefrontal cortex in schizophrenia revisited. Cereb.Cortex, 10, 1078-1092.

Callicott, J. H., Egan, M. F., mattay, V. S., Bertolino, A., Bone, A. D., Verchinksi, B. et al. (2003). Abnormal fMRI response of the dorsolateral prefrontal cortex in cognitively intact siblings of patients with schizophrenia. Am.J Psychiatry, 160, 709-719.

Callicott, J. H., Straub, R. E., Pezawas, L., Egan, M. F., Mattay, V. S., Hariri, A. R. et al. (2005). Variation in DISC1 affects hippocampal structure and function and increases risk for schizophrenia. Proc.Natl.Acad.Sci.U.S.A, 102, 8627-8632. 
Camps, M., Cortes, R., Gueye, B., Probst, A. \& Palacios, J. M. (1989). Dopamine receptors in human brain: autoradiographic distribution of D2 sites. Neuroscience, 28, 275-290.

CAnnon, T. D., Hennah, W., VAn ERP, T. G., Thompson, P. M., LONnQVist, J., HuTtunen, M. et al. (2005). Association of DISC1/TRAX haplotypes with schizophrenia, reduced prefrontal gray matter, and impaired short- and long-term memory. Arch.Gen.Psychiatry, $62,1205-1213$.

Chen, J., LipskA, B. K., Halim, N., MA, Q. D., MAtsumoto, M., Melhem, S. et al. (2004). Functional analysis of genetic variation in catechol-O-methyltransferase (COMT): effects on mRNA, protein, and enzyme activity in postmortem human brain. Am.J.Hum.Genet., 75, 807-821.

CHEN, Y. L. R., YU, H. E., CHEN, MAK, F. \& LIEH (2000). Semantic verbal fluency deficit as a familial trait marker in schizophrenia. Psychiatry Research, 95, 133-148.

Ciliax, B. J., Heilman, C., Demchyshyn, L. L., PRistupa, Z. B., InCE, E., Hersch, S. M. et al. (1995). The dopamine transporter: immunochemical characterization and localization in brain. J Neurosci., 15, 1714-1723.

Comings, D. E., Wu, S., CHIU, C., RING, R. H., GADE, R., AHN, C. et al. (1996). Polygenic inheritance of Tourette syndrome, stuttering, attention deficit hyperactivity, conduct, and oppositional defiant disorder: the additive and subtractive effect of the three dopaminergic genes - DRD2, D beta H, and DAT1. Am.J.Med.Genet., 67, 264-288.

Cortes, R., Gueye, B., Pazos, A., Probst, A. \& Palacios, J. M. (1989). Dopamine receptors in human brain: Autoradiographic distribution of D1 sites. Neuroscience, 28, 263-273.

Costafreda, S. G., Fu, C. H., Lee, L., EveritT, B., Brammer, M. J. \& DAVid, A. S. (2006). A systematic review and quantitative appraisal of fMRI studies of verbal fluency: role of the left inferior frontal gyrus. Hum.Brain Mapp., 27, 799-810.

Cragg, S. J. \& RICE, M. E. (2004). DAncing past the DAT at a DA synapse. Trends in Neurosciences, $27,270-277$.

Curtis, V. A., Bullmore, E. T., Brammer, M. J., Wright, I. C., Williams, S. C., MORRIS, R. G. et al. (1998). Attenuated frontal activation during a verbal fluency task in patients with schizophrenia. Am.J.Psychiatry, 155, 1056-1063.

DAmasio, A. R. \& DAMASiO, H. (1992). Brain and language. Sci.Am., 267, 88-95.

DiAmond, A., BRIAND, L., Fossella, J. \& GEHLBACH, L. (2004). Genetic and neurochemical modulation of prefrontal cognitive functions in children. Am.J.Psychiatry, 161, 125-132.

Diaz-AnzalduA, A., Joober, R., Riviere, J. B., DiOn, Y., Lesperance, P., RiCher, F. et al. (2004). Tourette syndrome and dopaminergic genes: a family-based association study in the French Canadian founder population. Mol.Psychiatry, 9, 272-277.

Drabant, E. M., HARiri, A. R., Meyer-Lindenberg, A., Munoz, K. E., MATTAY, V. S., KOLACHANA, B. S. et al. (2006). Catechol O-methyltransferase val158met genotype and neural mechanisms related to affective arousal and regulation. Arch.Gen.Psychiatry, 63, 1396-1406.

EgAn, M. F., Goldberg, T. E., GSCheidle, T., Weirich, M., RAWlings, R., Hyde, T. M. et al. (2001a). Relative risk for cognitive impairments in siblings of patients with schizophrenia. Biol.Psychiatry, 50, 98-107.

Egan, M. F., Goldberg, T. E., Kolachana, B. S., CAllicotT, J. H., Mazzanti, C. M., STraub, R. E. et al. (2001b). Effect of COMT Val108/158 Met genotype on frontal lobe function and risk for schizophrenia. Proc.Natl.Acad.Sci.U.S.A, 98, 6917-6922. 
FAraone, S. V., Perlis, R. H., Doyle, A. E., Smoller, J. W., Goralnick, J. J., Holmgren, M. A. et al. (2005). Molecular genetics of attention-deficit/hyperactivity disorder. Biol. Psychiatry, 57, 1313-1323.

FAraone, S. V., Seidman, L. J., Kremen, W. S., ToOmey, R., Pepple, J. R. \& Tsuang, M. T. (2000). Neuropsychologic functioning among the nonpsychotic relatives of schizophrenic patients: the effect of genetic loading. Biol.Psychiatry, 48, 120-126.

FIEZ, J. A. \& PETERSEN, S. E. (1998). Neuroimaging studies of word reading. Proc.Natl.Acad. Sci.U.S.A, 95, 914-921.

Fletcher, P. C., Frith, C. D., Grasby, P. M., Friston, K. J. \& Dolan, R. J. (1996). Local and distributed effects of apomorphine on fronto-temporal function in acute unmedicated schizophrenia. J.Neurosci., 16, 7055-7062.

FRISTON, K. J. (2003). Introduction: Experimental design and statistical parametric mapping. In R. S. Frackowiak, K. J. Friston, C. D. Frith, R. J. Dolan, C. J. Price, S. Zeki, J. Ashburner \& W. D. Penny (Eds.), Human Brain Function. 2nd ed., Academic Press.

FRISTON, K. J. \& FRITH, C. D. (1995). Schizophrenia: a disconnection syndrome? Clin.Neurosci., 3, 89-97.

FU, C. H., Morgan, K., Suckling, J., Williams, S. C., Andrew, C., Vythelingum, G. N. et al. (2002). A functional magnetic resonance imaging study of overt letter verbal fluency using a clustered acquisition sequence: greater anterior cingulate activation with increased task demand. Neuroimage., 17, 871-879.

Fu, C. H., SuCKling, J., Williams, S. C., Andrew, C. M., VYThelingum, G. N. \& MCGuire, P. K. (2005). Effects of psychotic state and task demand on prefrontal function in schizophrenia: an fMRI study of overt verbal fluency. Am.J.Psychiatry, 162, 485-494.

Fuke, S., SuO, S., TAKahashi, N., KoIKe, H., SASAgawa, N. \& ISHIURA, S. (2001). The VNTR polymorphism of the human dopamine transporter (DAT1) gene affects gene expression. Pharmacogenomics.J, 1, 152-156.

GERnSBACHER, M. A. \& KASCHAK, M. P. (2003). Neuroimaging studies of language production and comprehension. Annu.Rev.Psychol., 54, 91-114.

Gill, M., DAly, G., Heron, S., HAWI, Z. \& FitzGerald, M. (1997). Confirmation of association between attention deficit hyperactivity disorder and a dopamine transporter polymorphism. Mol.Psychiatry, 2, 311-313.

Glahn, D. C., Bearden, C. E., Niendam, T. A. \& Escamilla, M. A. (2004). The feasibility of neuropsychological endophenotypes in the search for genes associated with bipolar affective disorder. Bipolar.Disord., 6, 171-182.

Goldberg, T. E., EgAn, M. F., Gscheidle, T., Coppola, R., Weickert, T., KolachanA, B. S. et al. (2003). Executive subprocesses in working memory: relationship to catecholO-methyltransferase Val158Met genotype and schizophrenia. Arch.Gen.Psychiatry, 60, 889-896.

Goldberg, T. E., RAgland, J. D., TORRey, E. F., Gold, J. M., Bigelow, L. B. \& Weinberger, D. R. (1990). Neuropsychological assessment of monozygotic twins discordant for schizophrenia. Arch.Gen.Psychiatry, 47, 1066-1072.

Goldman, A. L., Pezawas, L., Mattay, V. S., Fischl, B., Verchinski, B. A., Zoltick, B. et al. (2008). Heritability of brain morphology related to schizophrenia: a large-scale automated magnetic resonance imaging segmentation study. Biol.Psychiatry, 63, 475-483.

GOLDMAN-RAKIC, P. S., Muly, E. C., III \& Williams, G. V. (2000). D(1) receptors in prefrontal cells and circuits. Brain Res.Brain Res.Rev., 31, 295-301.

GrACE, A. A. (2000). Gating of information flow within the limbic system and the pathophysiology of schizophrenia. Brain Res.Brain Res.Rev., 31, 330-341. 
GUR, R. E., KeShaVAN, M. S. \& LAWRIE, S. M. (2007). Deconstructing psychosis with human brain imaging. Schizophr.Bull., 33, 921-931.

Hall, J., Whalley, H. C., JOB, D. E., BAig, B. J., MCInTOSH, A. M., EVANS, K. L. et al. (2006). A neuregulin 1 variant associated with abnormal cortical function and psychotic symptoms. Nat.Neurosci., 9, 1477-1478.

Hariri, A. R., Goldberg, T. E., mattay, V. S., Kolachana, B. S., CAllicotT, J. H., EGAN, M. F. et al. (2003a). Brain-derived neurotrophic factor val66met polymorphism affects human memory-related hippocampal activity and predicts memory performance. $J$ Neurosci., 23, 6690-6694.

Hariri, A. R., MATtay, V. S., Tessitore, A., FerA, F. \& Weinberger, D. R. (2003). Neocortical modulation of the amygdala response to fearful stimuli. Biol.Psychiatry, 53, 494-501.

hariri, A. R., mattay, V. S., Tessitore, A., KolachanA, B., FerA, F., Goldman, D. et al. (2002). Serotonin transporter genetic variation and the response of the human amygdala. Science, 297, 400-403.

HARIRI, A. R. \& Weinberger, D. R. (2003b). Imaging genomics. Br.Med Bull, 65, $259-270$.

Hashimoto, R., Numakawa, T., OHnishi, T., Kumamaru, E., YAGasaki, Y., Ishimoto, T. et al. (2006). Impact of the DISC1 Ser704Cys polymorphism on risk for major depression, brain morphology and ERK signaling. Hum.Mol.Genet., 15, 3024-3033.

Heinz, A., Braus, D. F., Smolka, M. N., Wrase, J., Puls, I., HermanN, D. et al. (2005). Amygdala-prefrontal coupling depends on a genetic variation of the serotonin transporter. Nat.Neurosci., 8, 20-21.

Heinz, A., Goldman, D., Jones, D. W., Palmour, R., Hommer, D., Gorey, J. G. et al. (2000). Genotype influences in vivo dopamine transporter availability in human striatum. Neuropsychopharmacology, 22, 133-139.

HENRY, J. D. \& CRAWFORD, J. R. (2005). A meta-analytic review of verbal fluency deficits in schizophrenia relative to other neurocognitive deficits. Cognit.Neuropsychiatry, 10, $1-33$.

Howanitz, E., CiCAlese, C. \& HARvey, P. D. (2000). Verbal fluency and psychiatric symptoms in geriatric schizophrenia. Schizophr.Res., 42, 167-169.

Howes, O. D., Montgomery, A. J., Asselin, M. C., Murray, R. M., Grasby, P. M. \& MCGUIRE, P. K. (2007). Molecular imaging studies of the striatal dopaminergic system in psychosis and predictions for the prodromal phase of psychosis. Br.J Psychiatry Suppl, 51, s13-s18.

KARlsgodT, K. H., Glahn, D. C., VAN ERP, T. G., THERmAn, S., HUTTUnen, M., MANNinen, M. et al. (2007). The relationship between performance and fMRI signal during working memory in patients with schizophrenia, unaffected co-twins, and control subjects. Schizophr Res., 89, 191-197.

Kempf, L., Nicodemus, K. K., Kolachana, B., VAKKalanka, R., Verchinski, B. A., EGAN, M. F. et al. (2008). Functional polymorphisms in PRODH are associated with risk and protection for schizophrenia and fronto-striatal structure and function. PLoS.Genet., 4, e1000252.

Koten, J. W., JR., Wood, G., Hagoort, P., Goebel, R., Propping, P., Willmes, K. et al. (2009). Genetic contribution to variation in cognitive function: an FMRI study in twins. Science, 323, 1737-1740.

Kremen, W. S., Seidman, L. J., Pepple, J. R., Lyons, M. J., TsuAng, M. T. \& FARAOne, S. V. (1994). Neuropsychological risk indicators for schizophrenia: a review of family studies. Schizophr.Bull., 20, 103-119. 
LARUELLE, M. (2000). The role of endogenous sensitization in the pathophysiology of schizophrenia: implications from recent brain imaging studies. Brain Res.Rev., 31, 371-384.

Laruelle, M. \& ABI-DARgham, A. (1999). Dopamine as the wind of the psychotic fire: new evidence from brain imaging studies. J Psychopharmacol., 13, 358-371.

LARUElle, M., BI-DARGHAM, A., GIL, R., KegEles, L. \& INNIS, R. (1999). Increased dopamine transmission in schizophrenia: relationship to illness phases. Biol.Psychiatry, 46, 56-72.

Le Couteur, D. G., Leighton, P. W., Mccann, S. J. \& POND, S. (1997). Association of a polymorphism in the dopamine-transporter gene with Parkinson's disease. Mov Disord., $12,760-763$.

LeWis, D. A., Melchitzky, D. S., Sesack, S. R., Whitehead, R. E., Auh, S. \& SAmpson, A. (2001). Dopamine transporter immunoreactivity in monkey cerebral cortex: regional, laminar, and ultrastructural localization. J.Comp Neurol., 432, 119-136.

LINDVALL, O. \& BJORKLUND, A. (1978). Anatomy of the dopaminergic neuron systems in the rat brain. Adv.Biochem.Psychopharmacol., 19, 1-23.

MACDONALD, A. W., III, BECKER, T. M. \& CARTER, C. S. (2006). Functional magnetic resonance imaging study of cognitive control in the healthy relatives of schizophrenia patients. Biol.Psychiatry, 60, 1241-1249.

malhotra, A. K., Kestler, L. J., Mazzanti, C., Bates, J. A., GoldberG, T. \& Goldman, D. (2002). A functional polymorphism in the COMT gene and performance on a test of prefrontal cognition. Am.J.Psychiatry, 159, 652-654.

MANOACH, D. S., GOllub, R. L., BenSON, E. S., SEARl, M. M., GOFF, D. C., HAlPern, E. et al. (2000). Schizophrenic subjects show aberrant fMRI activation of dorsolateral prefrontal cortex and basal ganglia during working memory performance. Biol.Psychiatry, $48,99-109$.

martinez, D., Gelernter, J., Bi-DARgham, A., VAn DyCK, C. H., Kegeles, L., INNis, R. B. et al. (2001). The variable number of tandem repeats polymorphism of the dopamine transporter gene is not associated with significant change in dopamine transporter phenotype in humans. Neuropsychopharmacology, 24, 553-560.

MASSON, J., RiAD, M., ChAUdhry, F., DARMON, M., AIDOUnI, Z., CONRATH, M. et al. (1999). Unexpected localization of the $\mathrm{Na}+\mathrm{Cl}$--dependent-like orphan transporter, Rxt1, on synaptic vesicles in the rat central nervous system. Eur.J Neurosci., 11, 1349-1361.

mattay, V. S., Goldberg, T. E., Fera, F., Hariri, A. R., Tessitore, A., EgAN, M. F. et al. (2003). Catechol O-methyltransferase val158-met genotype and individual variation in the brain response to amphetamine. Proc.Natl.Acad.Sci.U.S.A, 100, 6186-6191.

MCGowan, S., LaWrence, A. D., SAles, T., Quested, D. \& GRASBy, P. (2004). Presynaptic dopaminergic dysfunction in schizophrenia: a positron emission tomographic [18F] fluorodopa study. Arch Gen Psychiatry, 61, 134-142.

MCKiernan, K. A., D'Angelo, B. R., KAUfman, J. N. \& Binder, J. R. (2006). Interrupting the "stream of consciousness": an fMRI investigation. NeuroImage, 29, 1185-1191.

MELTZER, H. Y. \& MCGURK, S. R. (1999). The effects of clozapine, risperidone, and olanzapine on cognitive function in schizophrenia. Schizophr.Bull., 25, 233-255.

Meyer-Lindenberg, A., Miletich, R. S., KOHN, P. D., EsPosito, G., CARson, R. E., QuarANTELLI, M. et al. (2002). Reduced prefrontal activity predicts exaggerated striatal dopaminergic function in schizophrenia. Nat.Neurosci., 5, 267-271.

Meyer-lindenberg, A., Nichols, T., CallicotT, J. H., Ding, J., Kolachana, B., BuckHOLTZ, J. et al. (2006). Impact of complex genetic variation in COMT on human brain function. Mol.Psychiatry, 11, 867-77, 797. 
MEYER-LindenBerg, A. \& WeInBERGER, D. R. (2006). Intermediate phenotypes and genetic mechanisms of psychiatric disorders. Nat.Rev.Neurosci., 7, 818-827.

Mill, J., Asherson, P., Browes, C., D'Souza, U. \& Craig, I. (2002). Expression of the dopamine transporter gene is regulated by the 3' UTR VNTR: Evidence from brain and lymphocytes using quantitative RT-PCR. Am J Med Genet, 114, 975-979.

MURAMATSU, T. \& HIGUCHI, S. (1995). Dopamine transporter gene polymorphism and alcoholism. Biochem.Biophys.Res.Commun., 211, 28-32.

PAPANICOlAOU, A. (1998). Fundamentals of Functional Brain Imaging: A Guide to the Methods and Their Applications to Psychology and Behavioral Neuroscience. Swets \& Zeitlinger.

Paunio, T., Tuulio-henriksson, A., hiekkalinna, T., Perola, M., Varilo, T., Partonen, T. et al. (2004). Search for cognitive trait components of schizophrenia reveals a locus for verbal learning and memory on $4 \mathrm{q}$ and for visual working memory on $2 \mathrm{q}$. Hum. Mol.Genet., 13, 1693-1702.

PENNY, W. D., Holmes, A. P. \& FRISTON, K. J. (2003). Random effects analysis. In R. S. Frackowiak, K. J. Friston, C. D. Frith, R. J. Dolan, C. J. Price, S. Zeki, J. Ashburner \& W. D. Penny (Eds.), Human Brain Function. (2nd ed.), Academic Press.

Perlstein, W. M., CARTER, C. S., NOlL, D. C. \& COHEN, J. D. (2001). Relation of prefrontal cortex dysfunction to working memory and symptoms in schizophrenia. Am.J.Psychiatry, 158, 1105-1113.

Pezawas, L., Meyer-Lindenberg, A., Drabant, E. M., Verchinski, B. A., Munoz, K. E., KOLACHANA, B. S. et al. (2005). 5-HTTLPR polymorphism impacts human cingulateamygdala interactions: a genetic susceptibility mechanism for depression. Nat.Neurosci., $8,828-834$.

PicChioni, M. M., CurTis, V. A., FU, C. H. Y., Ahmad, F., Chitnis, X., TOulopoulou, T. et al. (2001). Verbal fluency as a familial trait marker in schizophrenia: a twin fMRI study. NeuroImage, 13, 1086.

Porteous, D. J., Thomson, P., Brandon, N. J. \& Millar, J. K. (2006). The genetics and biology of DISC1--an emerging role in psychosis and cognition. Biol.Psychiatry, 60, 123-131.

Prata, D. P., Mechelli, A., FU, C. H., Picchioni, M., KANe, F., KAlidindi, S. et al. (2008). The DISC1 Ser704Cys polymorphism is associated with prefrontal function in healthy individuals. Mol.Psychiatry, 13, 909.

PRATA, D. P., MECHELli, A., FU, C. H. Y., PICCHIONI, M., KANE, F., KALIDINDI, S. et al. (2009c). Opposite Effects of Catechol-O-Methyltransferase Val158Met on Cortical Function in Healthy Subjects and Patients with Schizophrenia. Biological Psychiatry, 65, 473-480.

Prata, D. P., Mechelli, A., Fu, C. H., Picchioni, M., TOulopoulou, T., Bramon, E. et al. (2009a). Epistasis between the DAT 3' UTR VNTR and the COMT Val158Met SNP on cortical function in healthy subjects and patients with schizophrenia. Proc.Natl.Acad. Sci.U.S.A, 106, 13600-13605.

Prata, D. P., MEChelli, A., PiCChioni, M., FU, C. H. Y., KANE, F., KAlidindi, S. et al. (2011). No association of Disrupted-in-Schizophrenia-1 variation with prefrontal function in patients with schizophrenia and bipolar disorder. Genes Brain and Behavior, 10, 276-285.

Prata, D. P., MeChelli, A., Picchioni, M. M., FU, C. H., TOUlopoulou, T., Bramon, E. et al. (2009b). Altered effect of dopamine transporter 3'UTR VNTR genotype on prefrontal and striatal function in schizophrenia. Arch Gen Psychiatry, 66, 1162-1172.

PRICE, C. J. \& CRINION, J. (2005). The latest on functional imaging studies of aphasic stroke. Curr.Opin.Neurol., 18, 429-434. 
RUFF, R. M., EVANS, R. \& MARSHALL, L. F. (1986). Impaired verbal and figural fluency after head injury. Arch.Clin.Neuropsychol., 1, 87-101.

SESACK, S. R., HAWrylak, V. A., GUIDO, M. A. \& LEVEY, A. I. (1998). Cellular and subcellular localization of the dopamine transporter in rat cortex. Adv.Pharmacol., 42, 171-174.

SESACK, S. R. \& CARR, D. B. (2002). Selective prefrontal cortex inputs to dopamine cells: implications for schizophrenia. Physiology \& Behavior, 77, 513-517.

SESACK, S. R. \& PICKEL, V. M. (1992). Prefrontal cortical efferents in the rat synapse on unlabeled neuronal targets of catecholamine terminals in the nucleus accumbens septi and on dopamine neurons in the ventral tegmental area.J Comp Neurol., 320, 145-160.

Sitskoorn, M. M., Aleman, A., Ebisch, S. J. H., Appels, M. C. M. \& KaHn, R. S. (2004). Cognitive deficits in relatives of patients with schizophrenia: a meta-analysis. Schizophrenia Research, 71, 285-295.

Slifstein, M., Kolachana, B., Simpson, E. H., TABARes, P., Cheng, B., Duvall, M. et al. (2008). COMT genotype predicts cortical-limbic D1 receptor availability measured with [(11)C]NNC112 and PET. Mol.Psychiatry.

SMALL, G. W. (2006). Diagnostic issues in dementia: neuroimaging as a surrogate marker of disease. J Geriatr.Psychiatry Neurol., 19, 180-185.

Smolka, M. N., Schumann, G., Wrase, J., Grusser, S. M., Flor, H., MANN, K. et al. (2005). Catechol-O-methyltransferase val158met genotype affects processing of emotional stimuli in the amygdala and prefrontal cortex. J.Neurosci., 25, 836-842.

SOMMER, I. E., RAMSEY, N. F. \& KAHN, R. S. (2001). Language lateralization in schizophrenia, an fMRI study. Schizophr.Res., 52, 57-67.

SOMMER, I. E., RAMSEY, N. F., MANDL, R. C., VAN OEL, C. J. \& KAHN, R. S. (2004). Language activation in monozygotic twins discordant for schizophrenia. Br.J Psychiatry, 184, 128-135.

Spence, S. A., Liddle, P. F., Stefan, M. D., Hellewell, J. S., Sharma, T., Friston, K. J. et al. (2000). Functional anatomy of verbal fluency in people with schizophrenia and those at genetic risk. Focal dysfunction and distributed disconnectivity reappraised. Br.J.Psychiatry, 176, 52-60.

Sponheim, S. R., STEele, V. R. \& MCGuiRe, K. A. (2004). Verbal memory processes in schizophrenia patients and biological relatives of schizophrenia patients: intact implicit memory, impaired explicit recollection. Schizophr.Res., 71, 339-348.

TANAKA, S. (2006). Dopaminergic control of working memory and its relevance to schizophrenia: a circuit dynamics perspective. Neuroscience, 139, 153-171.

Thompson, P. M., CAnnon, T. D., NARr, K. L., VAn, E. T., POUTANen, V. P., HuTtunen, M. et al. (2001). Genetic influences on brain structure. Nat.Neurosci., 4, 1253-1258.

ToOmey, R., FAraone, S. V., Seidman, L. J., Kremen, W. S., PEPple, J. R. \& Tsuang, M. T. (1998). Association of neuropsychological vulnerability markers in relatives of schizophrenic patients. Schizophr.Res., 31, 89-98.

Tunbridge, E. M., HARRison, P. J. \& WeinBerGer, D. R. (2006). Catechol-o-methyltransferase, cognition, and psychosis: Val158Met and beyond. Biol.Psychiatry, 60, 141-151.

VAN Dyck, C. H., Malison, R. T., JAcobsen, L. K., Seibyl, J. P., STAley, J. K., LARuelle, M. et al. (2005). Increased dopamine transporter availability associated with the 9-repeat allele of the SLC6A3 gene. J Nucl.Med, 46, 745-751.

VAndenbergh, D. J., Persico, A. M., Hawkins, A. L., Griffin, C. A., Li, X., JABs, E. W. et al. (1992). Human dopamine transporter gene (DAT1) maps to chromosome $5 \mathrm{p} 15.3$ and displays a VNTR. Genomics, 14, 1104-1106. 
Vandenbergh, D. J., Thompson, M. D., CoOK, E. H., Bendahhou, E., NGuYen, T., KraSOWSKI, M. D. et al. (2000). Human dopamine transporter gene: coding region conservation among normal, Tourette's disorder, alcohol dependence and attention-deficit hyperactivity disorder populations. Mol.Psychiatry, 5, 283-292.

VANNESS, S. H., OWENS, M. J. \& KILTS, C. D. (2005). The variable number of tandem repeats element in DAT1 regulates in vitro dopamine transporter density. BMC.Genet, 6, 55.

WANG, G. J., VOlKow, N. D., FOWler, J. S., DinG, Y. S., LOGAN, J., GAlleY, S. J. et al. (1995). Comparison of two PET radioligands for imaging extrastriatal dopamine transporters in human brain. Life Sciences, 57, L187-L191.

WAYMENT, H. K., SCHENK, J. O. \& SORG, B. A. (2001). Characterization of extracellular dopamine clearance in the medial prefrontal cortex: role of monoamine uptake and monoamine oxidase inhibition. J Neurosci., 21, 35-44.

Weinberger, D. R., Berman, K. F. \& ChASe, T. N. (1988a). Mesocortical Dopaminergic Function and Human Cognition. Annals of the New York Academy of Sciences, 537, 330-338.

Weinberger, D. R., Berman, K. F. \& Chase, T. N. (1988b). Mesocortical dopaminergic function and human cognition. Ann.N.Y.Acad.Sci., 537, 330-338.

Weiss, E. M., Hofer, A., Golaszewski, S., Siedentopf, C., Brinkhoff, C., Kremser, C. et al. (2004). Brain activation patterns during a verbal fluency test - a functional MRI study in healthy volunteers and patients with schizophrenia. Schizophr.Res., 70, 287-291.

Whalley, H. C., SimonotTo, E., MoOrhead, W., MCIntosh, A., MARShall, I., Ebmeier, K. P. et al. (2006). Functional imaging as a predictor of schizophrenia. Biol.Psychiatry, 60, 454-462.

Whyte, M. C., Whalley, H. C., SimonotTo, E., FletT, S., Shillcock, R., MARShall, I. $e t$ al. (2006). Event-related fMRI of word classification and successful word recognition in subjects at genetically enhanced risk of schizophrenia. Psychol.Med., 36, 1427-1439.

Winterer, G., Musso, F., Vucurevic, G., Stoeter, P., Konrad, A., Seker, B. et al. (2006). COMT genotype predicts BOLD signal and noise characteristics in prefrontal circuits. Neuroimage., 32, 1722-1732.

WINTERER, G. \& WEINBERGER, D. R. (2004). Genes, dopamine and cortical signal-to-noise ratio in schizophrenia. Trends Neurosci., 27, 683-690.

YACubian, J., SOMmer, T., SCHroeder, K., Glascher, J., KAlisch, R., Leuenberger, B. et al. (2007). Gene-gene interaction associated with neural reward sensitivity. Proc.Natl. Acad.Sci.U.S.A, 104, 8125-8130. 